\title{
Chromosomal analysis in IVF: just how useful is it?
}

\author{
Darren K Griffin ${ }^{1}$ and Cagri Ogur ${ }^{2,3}$ \\ ${ }^{1}$ School of Biosciences, Centre for Interdisciplinary Studies of Reproduction, University of Kent, Canterbury, UK, \\ ${ }^{2}$ Bahceci Genetic Diagnosis Center, İstanbul, Turkey and ${ }^{3}$ Department of Bioengineering, Yildiz Technical University, \\ İstanbul, Turkey
}

Correspondence should be addressed to D K Griffin; Email: d.k.griffin@kent.ac.uk

This paper is part of an Anniversary Issue celebrating 40 years of in vitro fertilization. The Guest Editor for this section was Professor Lord Robert Winston.

\begin{abstract}
Designed to minimize chances of transferring genetically abnormal embryos, preimplantation genetic diagnosis (PGD) involves in vitro fertilization (IVF), embryo biopsy, diagnosis and selective embryo transfer. Preimplantation genetic testing for aneuploidy (PGT-A) aims to avoid miscarriage and live born trisomic offspring and to improve IVF success. Diagnostic approaches include fluorescence in situ hybridization (FISH) and more contemporary comprehensive chromosome screening (CCS) including array comparative genomic hybridization (aCGH), quantitative polymerase chain reaction (PCR), next-generation sequencing (NGS) and karyomapping. NGS has an improved dynamic range, and karyomapping can detect chromosomal and monogenic disorders simultaneously. Mosaicism (commonplace in human embryos) can arise by several mechanisms; those arising initially meiotically (but with a subsequent post-zygotic 'trisomy rescue' event) usually lead to adverse outcomes, whereas the extent to which mosaics that are initially chromosomally normal (but then arise purely post-zygotically) can lead to unaffected live births is uncertain. Polar body (PB) biopsy is the least common sampling method, having drawbacks including cost and inability to detect any paternal contribution. Historically, cleavage-stage (blastomere) biopsy has been the most popular; however, higher abnormality levels, mosaicism and potential for embryo damage have led to it being superseded by blastocyst (trophectoderm - TE) biopsy, which provides more cells for analysis. Improved biopsy, diagnosis and freeze-all strategies collectively have the potential to revolutionize PGT-A, and there is increasing evidence of their combined efficacy. Nonetheless, PGT-A continues to attract criticism, prompting questions of when we consider the evidence base sufficient to justify routine PGT-A? Basic biological research is essential to address unanswered questions concerning the chromosome complement of human embryos, and we thus entreat companies, governments and charities to fund more. This will benefit both IVF patients and prospective parents at risk of aneuploid offspring following natural conception. The aim of this review is to appraise the 'state of the art' in terms of PGT-A, including the controversial areas, and to suggest a practical 'way forward' in terms of future diagnosis and applied research.

Reproduction (2018) 156 F29-F50
\end{abstract}

\section{Introduction}

All variants of preimplantation genetic diagnosis (PGD) are designed to minimize the chances of transferring genetically abnormal embryos formed after in vitro fertilization (IVF). The process involves referral and counseling of the couples, standard IVF treatment, oocyte pick-up, embryo culture and biopsy, genetic diagnosis and finally selective transfer of 'unaffected' embryos. Referral categories, however, largely fall into two groups: the first for the purpose of preventing transmission of monogenic disorders or specific chromosome abnormalities to offspring where one parent or both may be carrier(s). The origin of the predicted problem can be a mutant allele or a balanced chromosome translocation ('savior siblings' would also fall into this category) (Verlinsky et al. 2001). The second is with the intention of improving IVF success and reducing the incidence of spontaneous abortion and affected live births by nontargeted aneuploidy screening. This practice has been variously named preimplantation genetic screening (PGS), PGD for aneuploidy (PGD-A) and, more recently, preimplantation genetic testing for aneuploidy (PGT-A). This review will use the more contemporary terminology.

\section{Brief history}

The first applications of PGD in animals (Edwards \& Gardner 1967) and human IVF (Steptoe \& Edwards 1978) paved the way for the genetic analysis of human embryos, particularly with the popularization of techniques such as the polymerase chain reaction (PCR) and fluorescence in situ hybridization (FISH). However, 
it was not until 1990, when PGD was first successfully applied clinically, that human embryos were subjected to blastomere biopsy and the sex was diagnosed by the amplification of a Y-specific repeat sequence, using PCR. In this case, the motivation was to eliminate the transmission of $\mathrm{X}$-linked conditions in which the mother was a carrier (Handyside et al. 1990). In 1992, the first healthy birth was reported following PGD for an autosomal recessive disorder after the diagnosis of $\Delta \mathrm{F} 508$ mutation in the cystic fibrosis transmembrane conductance regulator (CFTR) gene (Handyside et al. 1992). Indeed, PGD is theoretically applicable for any monogenic disorder where the mutation is identifiable by molecular techniques. To date, PGD has been licensed for over 400 different conditions in the UK (human fertilization and embryology authority - HFEA, 2017, http://guide.hfea.gov.uk/pgd/, accessed on Sep 2017) including late-onset disorders, mitochondrial disorders, rare disorders and HLA-typing (Kahraman et al. 2014) and has resulted in the birth of thousands of healthy children (Harper et al. 2012). PGT-A, however, constitutes the majority of PGD cycles performed globally and is more controversial. Referral categories for PGT-A typically are couples undergoing IVF with indications of advanced maternal age (AMA), prior recurrent miscarriages, prior recurrent implantation failures (Findikli et al. 2006) and severe male factor infertility (Kahraman et al. 2006, Coates et al. 2015), which may cause increased aneuploidy. The overall aim is to reduce the risk of pregnancy loss and the birth of chromosomally abnormal children, decrease the time to pregnancy and improve IVF success per embryo transfer. Perhaps in the future, this might be applied to all patients undergoing IVF. According to the European Society of Human Reproduction and Embryology (ESHRE) PGD consortium data for 10-year period (1997-2007), out of more than 27,000 cycles that reached the oocyte retrieval stage, $61 \%$ were performed for PGT-A, $17 \%$ for monogenic disorders, $16 \%$ for chromosomal PGD, 4\% for sexing of X-linked disease and $2 \%$ for social sexing (Harper et al. 2012). Global figures are becoming more difficult to collate, but it has been estimated that approximately 100,000 PGD cycles have been performed worldwide over the past 23 years (www.pgdis.org) and nearly $80 \%$ of these cycles have been PGT-A (personal communication from numerous meetings including PGD International Society - PGDIS).

\section{Detecting chromosome abnormalities in IVF embryos for PGT-A}

Unlike monogenic PGD, the detection of chromosome copy number is usually genome-wide and non-targeted. The challenge is to detect as many chromosomes with high resolution as possible, including the detection of segmental abnormalities. In general terms, techniques involving FISH have given way to CCS approaches including aCGH and next-generation sequencing (NGS).

\section{Fluorescence in situ hybridization (FISH)}

FISH was initially introduced into the clinic in 1992 using $\mathrm{X}$ - and $\mathrm{Y}$-chromosomal probes to treat families at risk of transmitting sex-linked disorders (Delhanty et al. 1993, Griffin et al. 1993) for the determination of the sex of the embryos as an alternative to the PCRbased approach. Later in 1993, the first applications of FISH for aneuploidy screening were carried out, assessing chromosome copy numbers of chromosomes $\mathrm{X}, \mathrm{Y}, 13,18$ and 21 - the most common aneuploidies associated with live birth defects (Munné et al. 1993, Schrurs et al. 1993). The number of chromosomes that could be screened was limited by the spectral resolution of the filter sets and the fluorochromes (red, yellow, green, aqua and blue). Later, chromosomes most commonly associated with spontaneous abortions (16 and 22), were included within a different set (Fig. 1A). Although largely applied to couples within the usual PGT-A referral categories (AMA, recurrent miscarriage, recurrent implantation failure and severe male factor infertility), the FISH technique has also been used successfully in the diagnosis of unbalanced products, that is where balanced translocation carrier parents give rise to embryos with segmental aneuploidies. Mostly a combination of 1 centromeric and 2 subtelomeric probes or 2 centromeric and 1 sub-telomeric probe (typically a three-color strategy) has been used routinely in a targeted strategy for patients carrying balanced translocations (Munné et al. 2005). For carrier patients, there is a need for a preclinical work-up in order, both to confirm the rearrangement and to assess signal specificities. This serves to rule out any cross hybridizations by testing at least 10 metaphase and 100 interphase cells from peripheral blood.

Irrespective of the stage at which the biopsy is performed, the FISH technique has many drawbacks. The number of chromosomes that are screened is a proportion of the total, and the subjectivity of the method itself may increase the risk of false-positive and false-negative results, causing either the elimination of normal embryos being diagnosed as abnormal or the transfer of abnormal embryos being diagnosed as normal. FISH clinically has only been used to screen a maximum of 9-12 chromosomes and is thus able to detect only $60-80 \%$ of all aneuploid embryos (Munné et al. 2010). Given the fact that aneuploidy could affect any chromosome (Franasiak et al. 2014), FISH cannot reliably detect a significant proportion of the aneuploidies and segmental abnormalities present in embryos. Although there have been attempts to analyze 24 chromosomes by using FISH technique on human embryos (loannou et al. 2011, loannou et al. 2012 Fig. 1B-F), such an approach was fraught with technical 

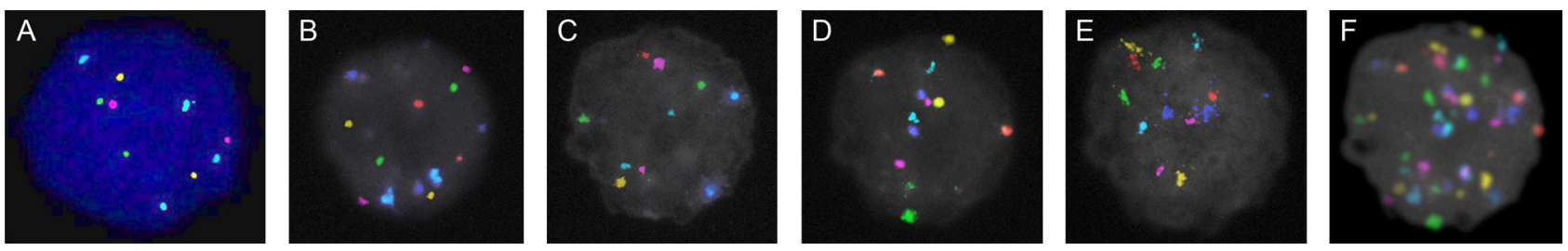

Figure 1 FISH on human embryos. (A) Classical 5 color $(13,16,18,21,22)$ of Munne et al. (B, C, D, E) subsequent hybridizatons of 6 color FISH, (F) merged image of 4 layers according to loannou et al. (2011).

problems, for example overlapping signals, failed probes and so forth, relegating it to the realms of a research tool only for investigating, for example nuclear organization and mosaicism when multiple cells are available for analysis (Turner et al. 2016). Other limitations include the success of the technique being dependent on the experience of the laboratory personnel performing critical laboratory procedures including embryo biopsy, blastomere fixation and analysis. These issues are considered to be one of the principal reasons that former randomized controlled trials (RCTs) have failed to show significant benefit of PGD in improving live birth rates (Mastenbroek et al. 2007, Twisk et al. 2008).

FISH still has a place for some types of translocations where the breakpoint is so distal that it cannot be diagnosed with any other PCR-based methods that suffer from resolution limitations. FISH also is still used in some PGD clinics for PGT-A. However, aCGH and NGS - see below - have largely replaced it.

\section{The need for whole genome amplification (WGA)}

Since the starting point for PGT-A is the DNA from a few cells (with only approximately 6pg DNA per cell), most CCS applications such as aCGH and NGS require WGA methods which break down into PCR-based methods such as degenerate oligonucleotide primed PCR (DOPPCR), non-PCR-based such as multiple displacement amplification (MDA) or a recently developed hybrid technique known as PicoPLEX and multiple annealing and looping based amplification cycles (MALBAC). The DOP-PCR method is the most commonly used and commercialized PCR-based protocol for PGT-A (SurePlex DNA Amplification System). MDA is a nonPCR, isothermal method for DNA amplification which involves the binding of random hexamers to denatured DNA followed by strand displacement synthesis at a constant temperature using the enzyme Phi 29 polymerase. Additional priming events can occur on each strand, leading to a network of branched DNA structures. Whereas in the hybrid method, MALBAC and PicoPLEX have an initial isothermal pre-amplification, in which common sequences are added, followed by PCR amplification using those sequences. Hybrid methods have been shown to have a higher level of uniformity, specificity and reproducibility and lower allele dropout (ADO) levels compared to MDA, in single-cell sequencing for the purpose of mutation detection (Chen et al. 2014, Li et al. 2017, Liu et al. 2018). However, for the detection of copy number variations such as aneuploidy, the SurePlex protocol still remains the most suitable one since MALBAC amplified samples show a high non-uniformity across the genome, which leads to false-positive results (Deleye et al. 2015).

\section{Comparative genomic hybridization (CGH)}

The $\mathrm{CGH}$ technique was introduced first as a means to screen chromosome copy number differences in solid tumors (Kallioniemi et al. 1992). CGH applies the principles of FISH using co-hybridization of differentially labeled test and reference DNAs with normal metaphase chromosomes. Unlike FISH, CGH facilitates assessment of chromosome copy number across the whole karyotype (Forozan et al. 1997), albeit with a limited resolution (Kirchhoff et al. 1998, Lichter et al. 2000). In an IVF setting, the technique was first successfully applied to blastomeres (Wells et al. 1999) but later described as laborious and time-consuming (Wells et al. 2002). Additionally, time constraints meant that it required freezing which was not sufficiently advanced at the time. Despite its limitations, this technique provided information about the entire copy number karyotype of embryos, which, for the first time, drew attention to the segmental aneuploidies and genomic instabilities in preimplantation development (Wilton et al. 2005). This comprehensive approach also provided a basis to develop aCGH technology and subsequently NGS.

\section{Array-CGH (aCGH)}

aCGH involves steps in common with chromosomal $\mathrm{CGH}$ such as WGA and fluorescent labeling of samples and a chromosomally normal reference (De Ravel et al. 2007); but rather than hybridization to metaphase chromosomes, the hybridization takes place on microarrays (bacterial artificial chromosomes or synthetic oligonucleotides) and the results are analyzed with specialized software (e.g. BlueFuse from Bluegnome - now Illumina - see Fig. 2). This method is fully automated, rapid and even compatible with blastocyst-stage biopsy and fresh transfer. The software analyzes the ratio of green and red fluorescent intensity signals in each chromosomal position, and then 

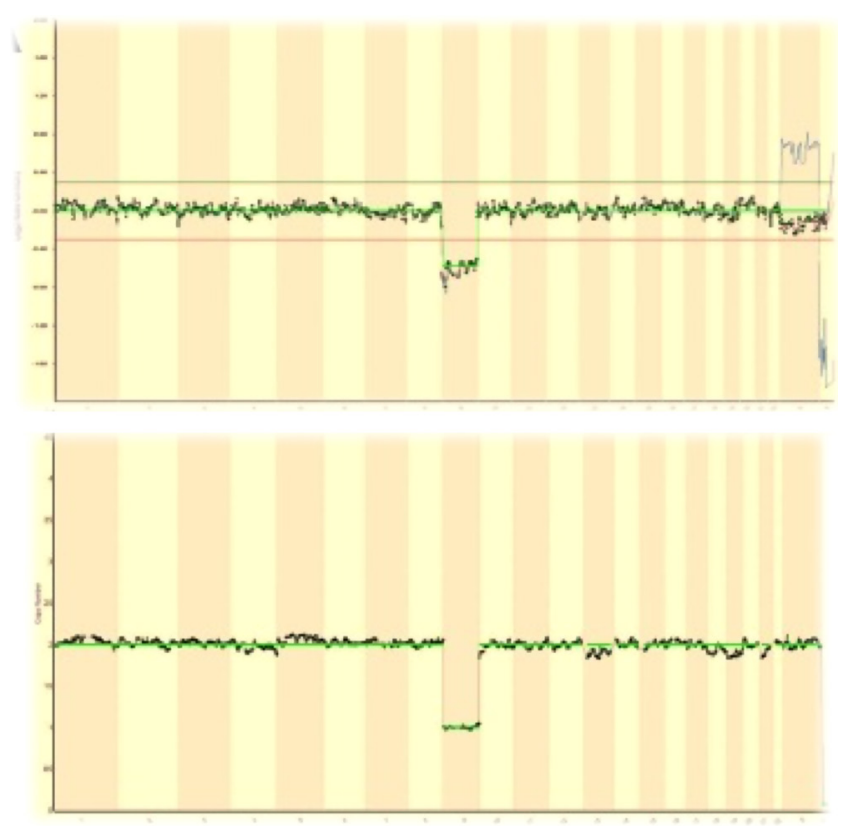

Figure 2 Comparison of aCGH (top) and NGS (bottom). This is the same WGA product (monosomy 9). The more specific trace and greater dynamic range are evident for NGS.

compares these ratios with those of a reference DNA sample. The calling of chromosomal status is achieved by the software by calculating the standard deviation ratios following so-called 'smoothing' and 'normalizing' the raw data. In addition to the numerical abnormalities (Le Caignec et al. 2006, Vanneste et al. 2009, Fishel et al. 2010, Traversa et al. 2011), this technique can detect segmental aneuploidies and imbalances that arise as a result of abnormal segregations due to rearrangements as small as $2.5 \mathrm{Mb}$ (Fiorentino et al. 2011). The aCGH technique has been applied successfully in all three biopsy stages, that is polar body (PB), cleavage and blastocyst stage, including proof of principle (Geraedts et al. 2011), preclinical validation (Johnson et al. 2010a), RCT (Yang et al. 2012) and retrospective case-control studies (Keltz et al. 2013).

Nonetheless, there are some pitfalls associated with $\mathrm{aCGH}$ and other techniques such as next-generation sequencing (NGS). These approaches cannot detect polyploidies, for example, triploidy and tetraploidy. Balanced chromosomal rearrangements, such as translocations, inversions and uniparental disomies (UPDs), cannot be detected because the relative ratios of chromosomal DNA are the same as those of the control DNA. Another disadvantage is resolution and their limited ability to detect mosaicism (Mamas et al. 2012).

\section{Next-generation sequencing}

Owing to its potential for scalability, NGS has recently been introduced into the clinic for aneuploidy screening to replace aCGH (Fiorentino et al. 2014, Wells et al. 2014, Zheng et al. 2015). Following WGA (in common with aCGH), a barcoding step follows to allow the identification of embryo-specific sequences (Knapp et al. 2012) after which the amplified product is broken down into small sequence-ready fragments. Those fragments are then subjected to massively parallel sequencing with low coverage for the purpose of aneuploidy screening. The number of reads per chromosome ('binning') is proportional to the copy number of each chromosome and serves as a basis for aneuploidy calls. With NGS, a large number of samples can be simultaneously tested, reducing the cost and workload. The NGS approach has the advantage of simultaneous assessment of aneuploidy, translocations, single-gene disorders, small copy number variations and low-level mosaicism $(<25 \%)$ from the same biopsy sample using the same platform technology (Fig. 2).

In order to assess the clinical impact of different diagnostic techniques, Maxwell et al. identified euploid embryos analyzed by aCGH that resulted in miscarriage. Of those embryos previously diagnosed as euploid by $\mathrm{aCGH}, 31.6 \%$ were mosaic and $5.2 \%$ were polyploid after analysis with high-resolution NGS. The authors suggested that NGS detects mosaicism and triploidy better than $\mathrm{aCGH}$, and this improvement in detection might have a positive impact on the clinical outcomes by decreasing the incidence of miscarriage (Maxwell et al. 2016). The superiority of NGS for the detection of mosaicism has been supported by another study where there were $6.7 \%$ in overall inconsistencies of mosaicism between two methods (Lai et al. 2017), NGS detected those not identified by aCGH. On the other hand, settings with a customized analysis software with a high specificity of detection of mosaicism might nonetheless pose a potential risk of overdiagnosing euploid embryos as mosaic. An increase in sensitivity may result in a decrease in specificity as has been observed by a recent study with significantly high (33\%) false-positive results (Goodrich et al. 2016).

NGS systems have the added advantage of simultaneously collecting both nuclear and mitochondrial DNA in the same sequencing run (Wells et al. 2014). mtDNA has been hypothesized as a biomarker associated with implantation and embryo viability, whereby lower quantities of mtDNA are associated with higher embryo implantation rates (Diez-Juan et al. 2015, Fragouli et al. 2015, 2017, Ravichandran et al. 2017). This finding is consistent with the 'Quiet Embryo Hypothesis' (Leese 2002) and suggests that the overall embryonic mtDNA content increases to meet the energy demand of an embryo with high energetic stress and low implantation potential, suggestive of a compensation mechanism for the respiratory chain defects that might result from high mutation levels (Monnot et al. 2013). However, there are some conflicting results opposing the notion of mtDNA as being used as a suitable biomarker for embryo viability such that there were no significant 
differences between implanted and non-implanted groups after a correction factor has been introduced (Victor et al. 2017) and the amount of mtDNA is not predictive for implantation where sibling embryos were used in a real-time quantitative PCR (RT-qPCR) system (Treff et al. 2017). The different platforms (either RT-PCR or NGS) and algorithms used in these studies might have accounted for these erratic results, making mtDNA assessment still a controversial subject (Ogur et al. 2017) that requires a standardized and reproducible approach.

\section{Real-time quantitative PCR (RT-qPCR)}

RT-qPCR technique is a robust, rapid, accurate and cost-effective CCS method. It has been developed and validated on TE biopsies (Treff et al. 2012, Treff \& Scott 2013). Briefly, first, a pre-amplification step involving the multiplex amplification of 96 loci is performed with the use of TaqMan copy number assays. The preamplified products are then quantified using RT-qPCR in a 384-well plate, and whole chromosome aneuploidies are determined. The whole procedure lasts about $4 \mathrm{~h}$ and can also be combined with mutation detection. In this approach, PCR is performed directly on the sample, without the need for a WGA step (Treff et al. 2012, Dahdouh et al. 2015a) which demonstrates the biggest advantage of this technique. However, the main drawbacks of this system are the facts that it is unable to detect segmental abnormalities and has yet to be validated for the detection of mosaicism.

\section{SNP arrays and Karyomapping}

Single-nucleotide polymorphism microarrays (SNP arrays) detect genetic variation across the genome and have been applied to human IVF embryos for the detection of chromosome abnormalities (Treff et al. 2011, Rabinowitz et al. 2012, Handyside 2015, Dahdouh et al. 2015a). Primarily developed to study genome- wide association (GWA), SNP arrays contain features of biallelic loci where each allele is of not dissimilar frequency (LaFramboise 2009). Interrogating SNP arrays leads to each feature being differentially labeled, thus detecting homozygotes and heterozygotes and a subsequent output at each point (Dahdouh et al. 2015a). Taking the SNP array output of each parent and a genetic relation of known disease status (typically an affected child), four distinct sets of markers can be identified across each parental chromosome (Handyside 2015). Karyomapping determines inheritance from parental/ grandparental haploblocks (inherited chromosomal segments). First, it involves identification of 'informative' loci for parental haplotype, that is where one parent is homozygous and the other heterozygous, like a classical 'back-cross' (Natesan et al. 2014a). Such loci are then compared to the reference DNA, and this 'establishes phase' (i.e. it assigns a reference 'affected' or 'unaffected' haplotype). After this, the genotype of each embryo is lined up against the reference to establish similarity or difference at each informative locus. This results in a 'Karyomap' that displays homologous chromosomes and points of genetic exchange facilitated by chiasmata (Fig. 3). Karyomapping is a diagnostic approach that involves simultaneous detection of monogenic and chromosomal disorders in one test (Handyside et al. 2010, Dahdouh et al. 2015a). The binary output of karyomapping makes this approach somewhat 'future proof' in that a shift from SNP array to NGS raw data is feasible in the future. Karyomapping has been validated using a blinded retrospective analysis by comparison with short tandem repeat marker and mutation detection approaches. The original three case reports, where karyomapping was run in parallel with conventional analysis for Smith-Lemli-Opitz syndrome, Marfan Syndrome and TSC2 (tuberous sclerosis) (Natesan et al. 2014b, Giménez et al. 2015, Thornhill et al. 2015), all led to unaffected, chromosomally normal live births, as well as demonstrating applicability to a subset of

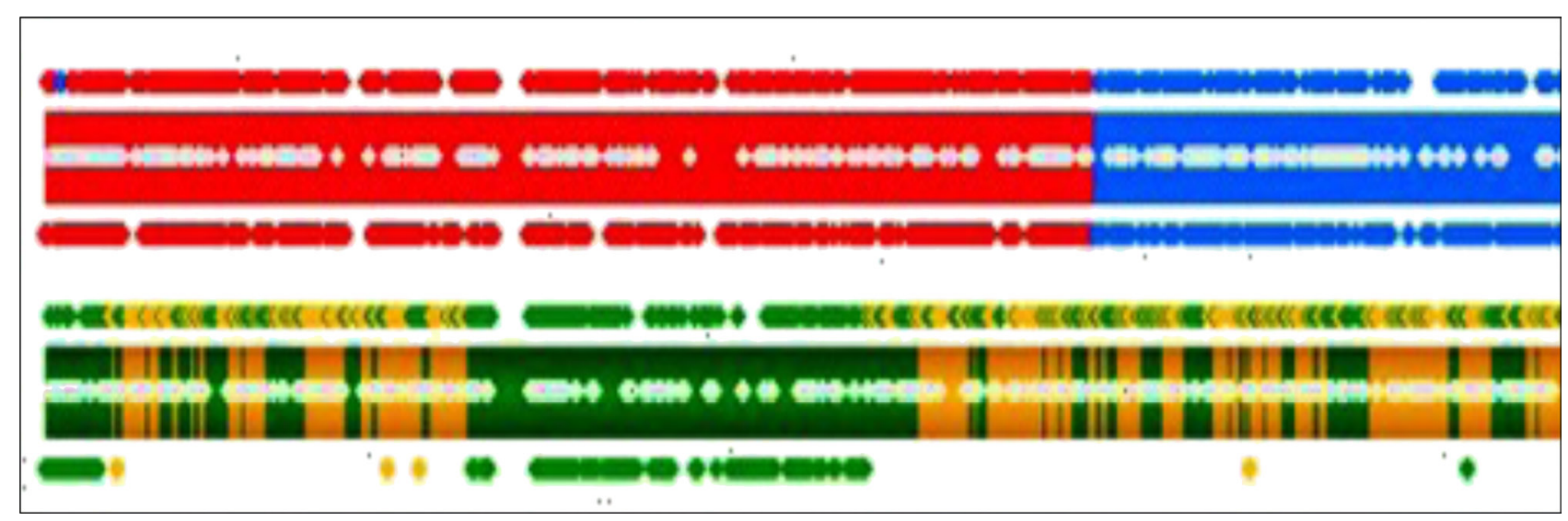

Figure 3 Karyomapping output. The red and blue blocks represent the paternal chromosomes with a cross over event occurring between two grandparental chromosomes. The variegated yellow and green blocks indicate a meiotic trisomy. 
de novo mutations undetectable using standard PGD strategies (Giménez et al. 2015). In an analysis of multiple cases that have been analyzed in parallel with direct mutation analysis, karyomapping analysis was concordant with mutation analysis in 213 of 218 embryos analyzed (97.7\%), with the exceptions being as a result of consanguinity (Natesan et al. 2014b).

Karyomapping can be used to diagnose meiotic trisomy, monosomy, triploidy, parthenogenetic activation, uniparental heterodisomy and patterns of genomic duplication observed in, for example, hydatidiform moles (Handyside et al. 2010, Natesan et al. $2014 a, b)$ but not post-zygotic trisomy (Fig. 3). Work is, however, now well underway to combine karyomapping alongside allele intensity measurements for the detection of non-meiotic trisomies and duplications (Zamani Esteki et al. 2015), thereby distinguishing meiosis I, meiosis II and post-zygotic errors (Giménez et al. 2015). This is clinically significant as mosaic trisomies where the initial error was meiotic in origin (followed by e.g. trisomy rescue) usually lead to clinical problems; however, those arising solely as a result of post-zygotic errors can, in certain circumstances, lead to unaffected live births (Wolstenholme 1996). Taken together, therefore, FISH, aCGH and NGS have all been instrumental in fundamental studies of the basic patterns of chromosome abnormalities in human development.

\section{What have the studies found in terms of aneuploidy and mosaicism?}

\section{Aneuploidy}

Aneuploidy in humans is, strictly speaking, defined as the deviation in the number of chromosomes from the usual 23 pairs $(2 \mathrm{n})$ resulting in either an excess (e.g., trisomy or tetrasomy), missing chromosome(s) (e.g., monosomy or nullisomy) or a combination of both (double aneuploidy, complex aneuploidy). This is distinct from haploidy (one set of chromosomes, $n$ ) and triploidy $(3 n)$, both of which are associated with abnormalities of whole chromosomal sets.

Aneuploidy is frequently observed in human preimplantation embryos and is the leading cause of reproductive failure and pregnancy loss in natural conceptions (Hassold \& Hunt 2001, Benkhalifa et al. 2005, Hodes et al. 2012). It can originate from a chromosome disjunction error in cell division either in meiosis or mitosis, or in both. The correlation between $\mathrm{AMA}$ and the risk of meiotic abnormalities has been well established since the association of conceiving a fetus with Down syndrome was first made (Penrose 1933). Accordingly, the incidence of aneuploidy in human embryos rises steadily with AMA. Indeed, in a large comprehensive chromosomal screening study, the proportion of aneuploid blastocysts was demonstrated to increase from $30 \%$ in women in their early 30 s to nearly
$90 \%$ in women aged 44 years and above (Franasiak et al. 2014). Prolonged exposure to environmental insult, the accumulation of reactive oxygen species (Tarín et al. 1996) and/or carbonyl stress that might affect mitochondrial integrity (Tatone et al. 2011) have all been postulated as possible causes for disturbed spindle formation and segregation of chromosomes during female meiosis. Moreover, live-cell imaging approaches have also been applied to study spindle formation and chromosome segregation dynamics directly in human oocytes. Such studies have introduced the concept of tri-directional anaphases, which are attributed to the loss of bipolar spindle structure at anaphase-I (Haverfield et al. 2017). There are further findings that spindle assembly is mediated by the chromosomes themselves as well as the small guanosine triphosphatase Ran (Holubcová et al. 2015). This long ( 16h) spindle assembly period is marked by an intrinsic instability of the meiotic spindle as well as abnormal kinetochore-microtubule attachments. These appear to favor chromosome segregation errors and provide a possible explanation for high rates of aneuploidy in human eggs. The result is classical non-disjunction of a whole chromosome or premature chromatid separation, leading to aneuploidy, especially in older women (Eichenlaub-Ritter et al. 2004), making AMA the leading referral category for PGT-A. Furthermore, the presence of aneuploidy in a significant proportion of embryos in donor cycles of younger women is sometimes given as evidence for the notion that PGT-A may be applicable to all IVF cycles, if performed correctly (Munné et al. 2006).

\section{Mosaicism}

Aneuploidy tends to be considered as a phenomenon that affects all cells uniformly in a conceptus. It nonetheless frequently occurs in a mosaic state, where there are at least two chromosomally distinct cell lineages present. In human embryos, it was first documented following the implementation of FISH for sex determination and aneuploidy screening (Griffin et al. 1992, 1993, Delhanty et al. 1993, Munné et al. 1994). A variety of different mechanisms have been implicated in the formation of mosaicism including predominantly mitotic non-disjunction, anaphase lagging, formation of microscopic nuclear abnormalities (e.g. multinuclei and micronucleus), centriole/centrosome dysregulation and endoreplication (Fig. 4) (Taylor et al. 2014, Kort et al. 2016, McCoy et al. 2015, Vázquez-Diez et al. 2018). Mitotic non-disjunction is the failure of separation of sister chromatids, resulting in 3:1 segregation, that is a cell with monosomy and another cell with trisomy. Anaphase lagging is the failure of a single chromatid to be incorporated into the nucleus, resulting in the loss of that chromosome in that particular cell. This creates a monosomic cell, while the other cell would have the two copies of that chromosome (Fig. 4). In mosaic embryos, the greater prevalence of monosomy 

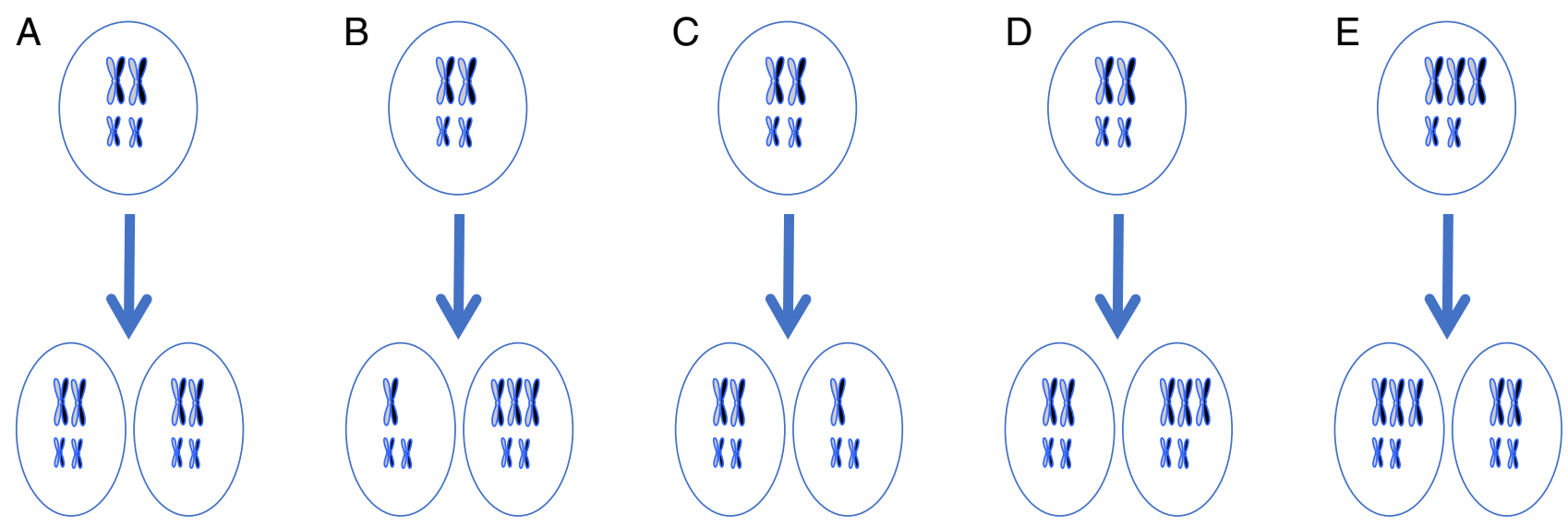

Figure 4 Main mechanisms leading to mosaicism: (A) normal segregation of chromosomes during mitosis. (B) mitotic non-disjunction event. (C) anaphase lagging event. (D) endoreplication event. (E) trisomy rescue (adapted from Taylor et al. 2014).

over trisomy has implicated anaphase lagging as the main mechanism of formation of mosaicism in embryos (Coonan et al. 2004, loannou et al. 2012, Capalbo et al. 2013a). More recently, generation of micronucleus (small nucleus like structures) subsequent to the appearance of lagging chromosomes has been proposed as a novel mechanism for the formation of mosaicism in mouse embryos (Vázquez-Diez et al. 2016). It has been shown that lagging chromosomes may form their own nuclear membrane in the resulting daughter cell. These micronucleus-enclosed chromosomes lack proper kinetochores which lead to abnormal segregation and generation of a cascade of aneuploid cells (Vázquez-Diez et al. 2018). Finally, endoreplication is another possible mechanism leading to mosaicism by the replication of chromosomes without subsequent division, creating two different (e.g. polyploid and diploid) cell lineages. To the best of our knowledge, however, endoreduplication of single chromosomes (as opposed to the whole genome) has not been described in any other eukaryotic cell type; it is therefore questionable whether this would be the case in embryos. Perhaps a more likely scenario for the occurrence of duplicated chromosomes is cytokinesis failure and/or mitotic slippage.

Not all mosaicism events originate solely from postzygotic abnormalities, however. A preexisting meiotic error (trisomy) can lead to a subsequent loss of a single trisomic chromosome, sometimes referred to as 'trisomy rescue.' Although the relative contributions of meiotic (followed by post-zygotic) vs solely post-zygotic mosaisicm are not well established, it is generally agreed that those initially arising in meiosis lead to more severe clinical outcomes, probably by virtue of the fact that more cells are affected. Moreover, this mechanism may account for some UPDs, which is seen in newborns at an incidence of 1 in 3500 (Robinson 2000).

In fact, the significant contribution of abnormal meiotic divisions as an original trigger of mosaicism in the embryo might have been underestimated; for example, a study with synaptonemal complex protein 3 (SYCP3) null mice, which are known to introduce chromosomal missegregation during meiosis, thereby producing aneuploid oocytes (Yuan et al. 2002), revealed that after fertilization, these aneuploid embryos become cytologically unstable, resulting in a rapid evolution of mosaicism and early embryonic death by apoptosis independent of P53 mechanism (Lightfoot et al. 2006). They concluded that most zygotes that originally inherit a whole chromosome aneuploidy from a karyotypically abnormal oocyte develop further chromosomal abnormalities during early development, generating a state of chaotic mosaic aneuploidy within the blastocyst (Lightfoot et al. 2006). These findings may suggest that there might be a common link between the mechanism leading to abnormal meiotic division and the formation of chaotic mosaicism where there are more than two chromosomally different cell lineages with an apparently random allocation of chromosomes in the daughter cells (Wells et al. 1999). This combined mechanism also might account to some extent for the loss of clinically unrecognized pregnancies.

Mosaicism is a common feature of human preimplantation development. In a systematic review, it was suggested that nearly three quarters of cleavagestage embryos are mosaic (van Echten-Arends et al. 2011), mostly (nearly 60\%) diploid-aneuploid mosaics containing euploid cells. Indeed, this high incidence of diploid-aneuploid mosaicism could be one of the reasons why cleavage stage for PGT-A (see later section) has been demonstrated to be ineffective or even harmful (Mastenbroek et al. 2007). However, most studies assessing the incidence of aneuploidy have been based on research on embryos not required for transfer, which were mostly diagnosed as abnormal already or developmentally compromised. Moreover, the predominant technique was FISH (see previous section) which is known to be more error-prone and limited compared to CCS. Indeed, in a study of 24 chromosome 
FISH, loannou et al. (2012) did not find a single nucleus with a clear 2 signals for each chromosome. Such technical drawbacks would thus likely impede any meta-analysis designed to reflect the true occurrence of mosaicism in cleavage-stage embryos. Despite this, a recent study using CCS techniques on good quality IVF embryos from young patients $(<35$ years) reported that $70 \%$ of cleavage-stage embryos have mosaicism (Mertzanidou et al. 2013). This might indicate that mosaicism is a common phenomenon in cleavage-stage embryos, irrespective of embryonic quality.

There is gathering evidence that the incidence of aneuploidy, including mosaicism decreases with the progression of embryos through later developmental stages. That is, mosaicism does occur in blastocyst embryos, but at lower levels (3.9\% to 33\%) (Johnson et al. 2010b, Northrop et al. 2010, Fragouli et al. 2011) than it does in cleavage-stage embryos. Several mechanisms have been proposed; developmental arrest of a significant proportion of mosaic embryos in cleavage stage and the cell death or reduced proliferation of aneuploid cells within an embryo may be responsible for the observed decrease of aneuploid blastomeres from compaction to blastocyst stage (Santos et al. 2010). There is also direct evidence revealed by mouse studies, that aneuploid cells were eliminated by apoptosis in the inner cell mass (ICM) prior to implantation and in the early developing embryo (Lightfoot et al. 2006). In another mouse model where mosaicism was generated by creating chimeric embryos, it was shown that mosaic embryos have full developmental potential based on their ability to self-correct via elimination of aneuploid cells by apoptosis depending on the lineage, provided they contain sufficient euploid cells (Bolton et al. 2016). Moreover, mosaicism rate is reported as less than $1-2 \%$ in viable pregnancies (Ledbetter et al. 1992), which suggests those mechanisms are still on play to remove abnormal cells from mammalian embryos in post-implantational period.

Although meiotic aneuploidy increases with AMA, there is no clear relationship between maternal age and mosaicism (van Echten-Arends et al. 2011, Mertzanidou et al. 2013, Turner et al. 2016). In fact, a paternal contribution to mosaicism may also be plausible since the disruption of the centrosome (paternally inherited) has been shown to result in mosaicism in preimplantation embryos (Palermo et al. 1997). In addition, some external factors such as culture conditions and ovarian hyperstimulation have been hypothesized to have a significant influence (Baart et al. 2007). At the same time, mosaicism rates vary greatly between centers (Munné et al. 2017), suggesting a role of, as yet unidentified, laboratory factors such as culture conditions. Such a hypothesis, however, needs further investigation as this finding, if corroborated, suggests a role for high-resolution aneuploidy screening as a quality assurance tool in IVF laboratories.

\section{The detection of mosaicism and its clinical implications}

The clinical consequences of mosaicism depend on variety of factors such as the timing of the segregation error, the proportion and the lineage of the embryo that has been affected and the type of abnormalities and the chromosome(s) involved (Wolstenhome 1996, Griffin et al. 1997). In general terms, an embryo would be predicted to be less severely affected when the error occurs at later stages of development, most likely resulting in confined mosaicism (Griffin et al. 1997). This is particularly relevant in that a meiotic error or one in the very earliest cleavage divisions would, most likely, be the most clinically significant, that is affecting the majority of cells in the embryo.

There is no clear consensus on the incidence of mosaicism in human preimplantation embryos. Rather, mosaicism tends to be reported when it is identified, for example in a TE biopsy of $5-10$ cells by NGS from an embryo containing between perhaps 60 and 150 cells. In a recent study attempting to stratify classifications of mosaicism, mosaicism levels lower than $20 \%$ of the cells tested were considered to be below the limits of detection of the technique used and the remaining embryo classified as euploid, between 20 and $40 \%$ as low mosaicism, $40-80 \%$ as high mosaicism and over $80 \%$ as aneuploid (Munné et al. 2017). Another study defined two groups in a way that embryos with mosaicism rates of $20-50 \%$ fall into one 'lower risk' category and those above $50 \%$ is considered as 'high risk' aneuploid and transfer avoided (Lai et al. 2017). Recently, the PGDIS published a position statement proposing $>20 \%$ as a cut-off point for definition of mosaicism when a highresolution NGS technique was used, such that lower levels of mosaicism $(<20 \%)$ should be treated as normal and the remaining ones between 20 and $80 \%$ as mosaic (euploid-aneuploid mosaics). It is noteworthy, however, that multiple ('chaotic') abnormalities in human embryos are a common phenomenon; these are usually mosaic (cells rarely have the same karyotype) and unlikely to lead to ongoing pregnancies.

Reported incidences of mosaicism in blastocysts vary greatly with the techniques used to assess it. Using 3 -chromosome FISH $(13,18,21)$ the overall mosaicism rate was reported as $10.5 \%$ and there was no preferential allocation of cells with abnormal chromosomes to the TE (Evsikov \& Verlinsky 1998). With 10-chromosome $\mathrm{FISH}$, the rate of mosaicism in cleavage-stage embryos was reported as $45-50 \%$ in blastocysts already diagnosed as abnormal (Baart et al. 2006). However, the more the number of chromosomes analyzed by FISH (12-24 chromosome FISH) (Ioannou et al. 2011, 2012), the greater the likelihood of technical errors associated with the technique itself.

Ideally, a CCS approach 'cell by cell' to assess the relative incidence of chromosome abnormalities in TE and ICM should give an idea of the true incidence of 
mosaicism. In order to investigate this, whole blastocysts need to be fully disaggregated and subjected to CCS with a 'map' created of the origin of each cell (ICM, polar TE and mural TE). According to an earlier study, only a relatively small proportion of mosaic embryos (Northrop et al. 2010) and only 9\% of all blastocyst tested were mosaic diploid-aneuploidy containing $>33 \%$ normal cells (Fragouli \& Wells 2011). In blastocysts of young patients, Johnson (2010b) observed that $96.1 \%$ of ICM were concordant with TE and there was only $3.9 \%$ mosaicism (discordancy) between TE and ICM. Indeed, there are only a limited number of studies reporting significant inconsistency between ICM and TE (Liu et al. 2012). Capalbo et al. (2013a) using an efficient immunostaining method to better characterize ICM and TE reported the rate of mosaic diploid-aneuploidy as $2.9 \%$ with no preferential allocation of abnormal cells between ICM and TE. To the best of our knowledge, however, there is only one small 'proof of principle' study (Taylor et al. 2016) in which blastocyst was separated first into ICM and 4 TE quadrants and then further disaggregated into individual cells.

Most studies thus suggest that the chromosome constitution of the TE is a reliable predictor of ICM karyotype (Johnson 2010b, Fragouli \& Wells 2011, Capalbo et al. 2013a). The relative benefits of different methodologies with different levels of sensitivities to detect mosaicism are discussed earlier. In brief, however, variation in reported mosaicism may appear because of WGA methods, different protocols, definitions, platforms, software, settings and laboratory-defined thresholds. For example, the aCGH platform (as explained earlier) fails to detect diploid-aneuploid mosaicism when $<25 \%$ cells in biopsy sample are abnormal (Mamas et al. 2012, Capalbo et al. 2013a). NGS technologies, however, appear to be more sensitive (Maxwell et al. 2016).

There is an ongoing debate on the merits of transferring mosaic embryos and the clinical impact. Given that, in mouse, mild levels of mosaicism do not affect developmental potential, while more severe levels of mosaicism significantly impair live birth rates as discussed earlier (Bolton et al. 2016), this raises the hypothesis that sufficient euploid cells present in the embryo enable the formation of a healthy fetus. In other words, the presence of a small number aneuploid cells does not necessarily jeopardize development (and perhaps even helps invasion of the TE into the uterine wall), which is possibly consistent with findings that frozen-thawed human embryos that have lost up a significant amount of their blastomeres due to cryopreservation process are nonetheless viable and can result in healthy live births (Zheng et al. 2008).

There are mainly four different developmental fates of mosaic embryos from a clinical point of view. A mosaic embryo may (i) fail to implant, (ii) implant and subsequently miscarry, (iii) result in the birth of abnormal child with genetic abnormalities and (iv) result in the birth of a healthy child (Greco et al. 2015). Although mosaic embryos have consistently been associated with lower implantation rates, a significant proportion of diploid-aneuploid mosaics can still produce viable pregnancies (30.1\%) (Fragouli et al. 2017). A recent study showed that after transferring 18 mosaic (range of $35-50 \%$ ) embryos, six of them resulted in normal live births (Greco et al. 2015). Further reports showed the transfer of 143 diploid-aneuploid mosaic embryos, resulting in a $53 \%$ implantation rate and $41 \%$ ongoing implantation rate and that the type of mosaic abnormality makes a significant contribution to the clinical outcome (Munné et al. 2017). Furthermore, an embryo with a mosaic cell lineage consisting of complex abnormalities has, as concluded, $10 \%$ lower chances of implantation compared to those with only single or double aneuploidies (Munné et al. 2017). Single chromosome aneuploidies in $20-40 \%$ of cells have an implantation rate of $56 \%$, whereas those harboring the abnormality in $40-80 \%$ of cells have an implantation rate of $22 \%$ (Munné et al. 2017) clearly, there is a need for more subtle and informed interpretation of mosaicism data.

In conclusion, current opinion states that 'Mosaic embryos may represent a third category between euploid and aneuploid embryos and could be considered for transfer under certain circumstances such that if there is no euploid embryos available for transfer' (Fig. 5) (Harton et al. 2017, Munné et al. 2017, Sachdev et al. 2017). PGDIS recommends the transfer of embryos showing mosaic monosomies (except 45,X0) over mosaic trisomies; but the idea has been opposed by Munné et al. (2017), showing that the two groups have very similar implantation potential. PGDIS guidelines also focus on which chromosomes affected by mosaicism should be avoided (i.e. when chromosomes $X, Y, 13,14,15,16,18,21$ are involved, either because they are more susceptible to UPD or compatible with live birth (The Preimplantation Genetic Diagnosis International Society, Personal communication). With current knowledge, the follow-up data from the transfer of mosaic embryos are insufficient to draw robust conclusions about the degree of mosaicism and which type of abnormalities involved may affect the viability of mosaic embryos. Further research is thus needed.

\section{The impact of sampling methods on PGT-A and the advantages of vitrification}

As for all PGD, there are currently three sources of cellular material that can be used for PGT-A: PBs from oocytes and zygotes; blastomeres from cleavage-stage embryos and TE cells from blastocysts (Thornhill \& Snow 2002). Ideally, timing of the biopsy should facilitate accurate identification of the genetic errors and the identified abnormalities in the biopsy material should correspond 

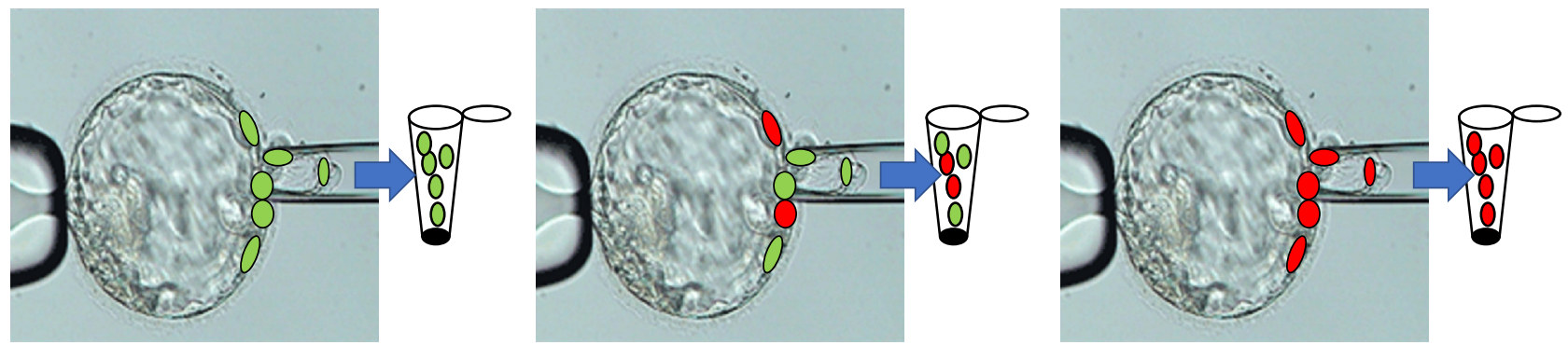

Euploid

Mosaic

Aneuploid

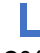

1

$50 \%$

$100 \%$

Figure 5 Suggested method for embryo scoring. Mosaic category of embryos should be evaluated as a third category and the different levels of mosaicism reported. This could potentially be used to avoid discarding viable embryos and prioritize mosaic embryos over aneuploid ones (adapted from Harton et al. 2017).

to an abnormality in the embryo (Thornhill \& Snow 2002). The timing of biopsy also impacts on the decision of whether to 'freeze all' embryos or transfer fresh in the first cycle and freeze the remainder. Moreover, noninvasive means of sampling are now being considered as alternatives to embryo biopsy.

\section{PB biopsy}

This technique was first introduced by Verlinsky et al. in 1990, to identify the oocytes that contain the maternal unaffected gene in women heterozygous for a genetic disease (Verlinsky et al. 1990). The PBs are the by-products of meiotic division, and their removal is unlikely to have any negative impact on the further development of the embryo. PBs could be removed either sequentially or simultaneously, after fertilization (Magli et al. 2011 - for a technical overview). However, the PBs may undergo rapid fragmentation, and any delay in biopsy timing might result in inefficient testing or misdiagnosis if not all the fragments are retrieved. The main advantages of PB biopsy are that it is less invasive than biopsying the whole embryo and it provides longer time for genetic analysis when the transfer is performed in the same fresh cycle. However, PBs cannot be used to diagnose paternal chromosomes or post-meiotic errors such as mosaicism and cannot be used for sex determination. For that reason, its applicability for PGT-A is limited to diagnose maternal meiotic abnormalities and translocations. PB biopsy has been on the rise in recent years when it was proposed as an alternative to cleavage-stage biopsy (Geraedts et al. 2010, 2011), after RCT studies that are based upon blastomere analysis were shown to have limited benefit (Mastenbroek et al. 2007, Hardarson et al. 2008). Indeed, the first successful live birth following CCS was performed after PB biopsy (Fishel et al. 2010).
Nevertheless, the capture of embryonic chromosome segregation errors and genetic abnormalities with $\mathrm{PB}$ biopsy is low and can only detect meiotic abnormalities. CCS analysis on the serial biopsies of embryos showed that nearly half of the embryos (47.6\%) had aneuploidies other than female meiotic-derived ones, and the sensitivity in predicting blastocyst chromosomal complement was found to be significantly lower using PB biopsy $(61.7 \%)$, compared with blastomeres analysis $(86.4 \%)$ $(P<0.01)$ (Capalbo et al. 2013b). PBs have been shown to have the least predictive value of embryo euploidy and implantation compared to both blastomeres and TE samplings in the same group (Salvaggio et al. 2014). In addition, prediction of the ploidy status of PBs with reciprocal aneuploidies (e.g. where there is a loss and a gain of the same chromosome in PB 1 and 2, respectively) poses another problem: reciprocal aneuploidies of the same chromosomes were found to be almost always euploid (Forman et al. 2013a). The distinction between double vs single chromatid losses/gains should thus be defined clearly and the predicted status of euploidy should be confirmed by further analysis at either cleavage or blastocyst stage. However, pooling both PBs before DNA amplification could demonstrate an alternative way to overcome this ambiguity (so the reciprocity outlined earlier would lead to a normal diagnosis - the disomy and nullisomy cancelling each other out), also lowering the cost of testing (Feichtinger et al. 2015).

Recently, in order to investigate the clinical efficiency of PGT-A in an RCT setting, the first multicenter RCT for 23 chromosome testing of PBs (using the aCGH platform) was conducted under the name of ESTEEM (ESHRE Study into The Evaluation of oocyte Euploidy by Microarray analysis) (NCT01532284) including women aged between 36 and 41 years. The initial results were described as disappointing as full chromosome analysis of both PBs would not increase the likelihood of a live 
birth within one year compared to controls. The only advantage of screening of PBs was the miscarriage rate in the PB biopsy group, which was substantially lower than that in no-intervention group (Brown 2017) and thus could prove to be sufficient incentive for some patients to undergo this procedure.

As a result of the aforementioned limitations, the lack of expertise in biopsy procedures and the doubled cost of genetic testing (PB1 and PB2 are tested separately), this technique has not been used as widely as cleavagestage and blastocyst-stage biopsy.

\section{Cleavage-stage (blastomere) biopsy}

Cleavage-stage (blastomere) biopsy is performed by the removal of one or two blastomeres on day 3 embryos with at least 6 blastomeres. $\mathrm{Ca}^{++} \mathrm{Mg}^{++}$-free media is used to facilitate the removal of the selected blastomere(s). One of the following three methods could be used to open the zona pellucida: laser-assisted, mechanical and chemical (acid Tyrodes) - with laser being the most widely used. With cleavage-stage biopsy, unlike for PBs, both maternal and paternal meiotic errors can be detected. In addition, cleavage-stage biopsy allows sufficient time for analysis to be performed before the embryo reaches the blastocyst stage and also sufficient time for a fresh transfer with the timely shipment of samples if transport PGD (i.e. sending samples to specialist diagnostic laboratories) is necessary. This technique has been the oldest and most widely used method for PGD, including PGT-A (Harper et al. 2012).

Cleavage-stage biopsy, however, suffers from both technical and biological problems. One of the most important ones is the aforementioned mosaicism rate, which is at its highest level in cleavage-stage embryos, irrespective of maternal age (Munné \& Wells 2017). In order to increase the detection of mosaicism, some centers use a two-cell biopsy approach, which often results in the loss of embryonic volume by at least $25 \%$. The possible damage of decreasing the cell number on the further development and reducing its implantation capability of the biopsied embryo needs to be balanced against the benefits of diagnostic tests that are used to enhance implantation rates (Cohen et al. 2007).

It is the use of cleavage-stage biopsy that has led to the greatest controversy in the world of PGT-A. Although initial retrospective studies of PGT-A involving cleavagestage biopsy were promising (Munné et al. 1993, Gianaroli et al. 2005), later RCTs demonstrated either no improvement or an adverse effect on IVF outcome when cleavage-stage biopsy was used (Mastenbroek et al. 2007, Schoolcraft et al. 2009). Herein lies the nature of the controversy: While some argue that it is PGT-A per se that should be discontinued on the basis of these results, others argue that it is cleavage-stage biopsy itself that is the problem. With a mean number of 8 cells at this stage, removing one (or even 2) could, in theory, reduce the chances of future embryo development compared to both PB and blastocyst biopsy; this could be operatordependent. Indeed, studies that demonstrated a decrease in implantation rate when compared to standard IVF without PGT-A were severely criticized on the basis that they caused damage as a result of the biopsy process. Indeed, one interpretation of the Mastenbroek et al. (2007) data is that there was a third group in the dataset that was only briefly mentioned in the manuscript, that is patients who had embryo biopsy but not PGT-A. A $6 \%$ live birth rate compared to $16.8 \%$ in the PGT-A group (and $14.7 \%$ in the control group) is evidence, some say, that it is the practice of cleavage-stage biopsy, perhaps in the hands of certain operatives, that is the underlying reason for the initial lack of success of PGT-A.

In order to assess the impact of cleavage stage biopsy on the developing embryos, an RCT with a paired design was performed (Scott et al. 2013a). In that study, the results demonstrated a relative $39 \%$ reduction in implantation rates in the cleavage-stage biopsy group with respect to controls. However, no measurable impact has been observed after TE biopsies where implantation and delivery rates were similar for the two groups (Scott et al. 2013a). There is also evidence from time-lapse analysis supporting the notion that the developmental dynamics are impaired after blastomere removal, causing delayed compaction and altered hatching in both human and mouse embryos (Duncan et al. 2009, Kirkegaard et al. 2012).

Another drawback of this technique is the relatively low amount of DNA material to analyze, which may increase the proportion of embryos with diagnostic failures and may increase the risk of false-negative/positive results since most of the comprehensive chromosomal analysis techniques still require PCRbased amplification methods. Thus, although cleavagestage biopsy has historically been the most commonly used method of biopsy (Harper et al. 2012, Cimadomo 2016), it is being largely discontinued and gradually replaced by blastocyst-stage biopsy whether the indication is PGT-A or PGD for single-gene disorders.

\section{Blastocyst-stage (TE) biopsy}

Compared to other techniques, blastocyst-stage biopsy (although around for many years) has only become widespread clinically after improved culture conditions have been implemented in IVF laboratories (Mc Arthur et al. 2005). Blastocyst-stage biopsy is most commonly performed by the retrieval of a small part of the TE which had herniated through the breach previously opened on day 3 by using assisted hatching techniques in order to facilitate the hatching process.

TE biopsy has many advantages over other biopsy methods. First, the blastocyst has $>100$ cells in it, and thus the removal of $2-10$ cells from the TE is less likely, in principle, to affect the viability of the embryo. As a result, the risk of diagnostic errors caused by 
technical problems such as amplification failures or the ADO is lower compared to that in cleavage-stage biopsy (Forman et al. 2011). Furthermore, mosaicism (see previous section) is observed at a lower rate in blastocysts compared to cleavage-stage embryos.

Blastocyst-stage embryos have a greater chance to be euploid and to implant compared to cleavage-stage embryos (Kokkali et al. 2007, Fragouli et al. 2008). By the use of this natural selective advantage, the genetic analysis of only those embryos that develop into blastocysts not only reduces the cost of the diagnosis, but also increases the implantation rate and reduces the risk of multiple pregnancies by means of a single euploid blastocyst transfer (Forman et al. 2013b, Ubaldi et al. 2015). In addition, the blastocyst biopsy technique may be less operator-dependent and can be more reproducible across different clinics (Capalbo et al. 2016). It should also be noted that RCTs demonstrating aneuploidy screening for all 24 chromosomes as beneficial were mostly conducted with TE biopsies (Yang et al. 2012, Forman et al. 2013b, Scott et al. 2013b) with the exception of one with cleavage stage (Rubio et al. 2017), which also demonstrated benefits.

\section{Impact of vitrification and freeze-all strategies on the choice of biopsy}

Since the time for the analysis is limited by the implantation window of the blastocyst, at first, the major drawback of the technique was thought to be the need for cryopreservation. However, the co-evolution of enhanced culture conditions and excellent vitrification techniques have led to better blastulation rates and thus more embryos available for TE biopsy and better survival after thaw (Cobo et al. 2012). Independent of PGD, the IVF world generally has seen improvement in embryo cryopreservation techniques which later impacted the world of PGT-A. Indeed, in recent years, there has been a move in the direction of embryo cryopreservation with a view to a later transfer (freeze-all) strategy in an unstimulated cycle (Dieamant et al. 2017). Thus, while increased pregnancy success rates have been attributed to the advancement of PGT-A technologies (improved blastocyst biopsy (previous section) and aCGH, NGS see next sections), some argue that credit may possibly be given to an improvement associated with frozen embryo transfer (Dieamant et al. 2017). Transfer of vitrifiedwarmed single blastocysts yields improved outcomes (Roy et al. 2014) and higher live birth rates $(77 \%$ vs $59 \%$ ) in the frozen group compared with the fresh group (Coates et al. 2017), which could be attributed to a better preparation of endometrium in the next cycle avoiding the possible detrimental effect of ovarian hyperstimulation on endometrial receptivity. There is a tight connection between the window of implantation and the endometrial transcriptome (Mahajan et al. 2015, Koot et al. 2016) where natural cycles have been shown to be superior over artificial cycles based on specific gene expression profiles (Altmäe et al. 2016). Therefore, transfer in subsequent freeze-thaw cycles may also allow for preparation of a more physiological and receptive endometrium (Dieamant et al. 2017).

\section{The prospects for non-invasive PGT-A Blastocentesis}

For the purpose of creating alternative sources for genetic diagnosis, there are also less-invasive approaches that do not involve the biopsy of cells. One of them is the aspiration of blastocoelic fluid (BF). The fluid contained in the blastocoleic cavity has been shown to contain DNA and various proteins responsible for regulation of several processes during development of the embryo (Gianaroli et al. 2014) and thus may represent an alternative source of material with minimally invasive approach. In this technique, BF is aspirated through an ICSI pipette, paying great attention to avoid the aspiration of any single cell. A volume of approximately $0.01 \mu \mathrm{L}$ $\mathrm{BF}$ is retrieved from each blastocyst and amplified by WGA (Gianaroli et al. 2014). In a study performed to investigate the potential of BF as a diagnostic sample, the DNA could be obtained in $82 \%$ of the sampled fluids, and $97.1 \%$ of the diagnosis results were in concordance with TE cells (Magli et al. 2016). This study is also important in the way it tested the applicability of non-invasive PGD on translocation carriers where the diagnosis of segmental abnormalities is required and is more challenging. Unfortunately, there were also falsepositive and false-negative errors associated with the technique and it has yet to be validated for the detection of mosaicism. Although it is promising, the technique requires improvements before it is used as a routine alternative source of genetic testing.

\section{Analysis of spent culture medium}

The idea of analyzing spent culture medium as a method to gain insight on an embryo's developmental competence non-invasively has been discussed in the literature for some years (e.g. Sturmey et al. 2008). A key breakthrough in this direction was described in 2002 when it was demonstrated that the pattern in which embryos modify the amino acid content of the culture medium is predictive of their ability to develop to the blastocyst stage (Houghton et al. 2002). Further investigation found that the pattern of amino acid consumption, and particularly that of asparagine, glycine and leucine, was also related to the ability of the embryo to establish an ongoing pregnancy (Brison et al. 2004).

Recently, however, the prospects of analysis of spent media for the purposes of PGT-A have become apparent. Liu et al (2017) achieved both non-invasive 
PGT-A and diagnosis of beta thalassemia simultaneously using analysis of cell-free nuclear DNA spent embryo culture medium in 88 donated embryos from 7 couples. Reporting a DNA detection rate of over $90 \%$, the full chromosome concordance rate between biopsied cells and medium was $\sim 65 \%$, increasing to $90 \%$ for diploid blastocyst samples (Liu et al. 2017). Shamonki et al. (2016) also provided proof of concept of a similar approach. Analyzing embryos from 7 couples and 57 embryos and comparing with TE biopsy for PGT-A, they found all but 2 had detectable DNA and a small number corresponded with the original diagnosis. Feichtinger et al. (2017) analyzed media from 22 blastocysts, reporting a $72 \%$ 'general' concordance rate (i.e. euploid or aneuploid) and a little under 50\% exact concordance with PB biopsied samples. Similarly, Xu et al. (2016) used MALBAC amplification and NGS (the others used $\mathrm{aCGH}$ ) on the spent culture medium. A positive predictive value of $79 \%$ and negative predictive value of 91\% were reported. Such an approach avoids the need for embryo biopsy which, as indicated earlier, has the potential to damage the embryo. Nevertheless, there are several potential sources of contamination that may contribute to the genetic material detected in the culture medium (Hammond et al. 2016) and before it is put into full clinical use, it needs to be validated against 'gold standard' approaches.

\section{Morphokinetics and time lapse for aneuploidy detection}

Another technique that aims to select the best embryo for implantation is continuous monitoring via time-lapse imaging technology, which allows non-invasive embryo observation without the need to remove the embryo from optimal culture conditions. It has been suggested that chromosomally normal and abnormal embryos tend to have different kinetic behaviors (Chavez et al. 2012, Campbell et al. 2013a, Basile et al. 2014, Chawla et al. 2015). According to results of studies based on both cleavage stage (Chavez et al. 2012, Basile et al. 2014, Chawla et al. 2015) and blastocyst-stage biopsy (Campbell et al. 2013a), euploid embryos tend to follow a more defined pattern. Precise cell cycle parameter timing is observed in all euploid embryos to the fourcell stage, whereas only $30 \%$ of aneuploid embryos fell within the proposed window (Chavez 2012). Euploid embryos required a significantly shorter time to the initiation of compaction, time to start blastulation (tSB) and to full blastulation (tB) (Campbell et al. 2013a). Even some subtypes of chromosomal abnormalities such as complex aneuploidy have been associated with embryo morphokinetics (t3 and t5) (Del Carmen Nogales et al. 2017).

There are, nonetheless, some conflicting data. In a well-designed prospective study using sibling oocytes, and blastocyst-stage biopsy, Yang and colleagues reported no significant differences between euploid and aneuploid embryos in terms of morphokinetic parameters $(t 2, t 3, t 5, C C 2, s 2 ; t 8, t M, t I B, t F B, t E B)$ of both early and later stages of embryonic development (Yang et al. 2014). In another study with cleavage-stage biopsy, a higher proportion of normal embryos fell within the optimal ranges defined for $\mathrm{t} 5, \mathrm{CC} 3$ and $\mathrm{t} 5 \mathrm{-t} 2$, but it did not reach significance (Patel et al. 2016). The reason for the conflicting data could be the different stages of biopsy used by different groups and the inadequacy of the sample sizes (Patel et al. 2016).

There is also some evidence demonstrating that morphokinetic parameters are concordant with implantation potential (Meseguer et al. 2011, Campbell 2013b, Yang et al. 2014, Patel et al. 2016) when applied on the same model that has been used to classify embryos as having high, medium and low ( $\mathrm{tB}>122.9$ and $\mathrm{tSB}>96,2 \mathrm{~h}$ ) risk of being aneuploid. Significant relative increases in live birth rates were demonstrated when an embryo retrospectively classified as low risk was transferred (Campbell 2013b). However, this study was later criticized for possibly being affected by confounding factors such as age (Ottolini et al. 2014).

In conclusion, use of time-lapse monitoring, although not being able to predict the ploidy status of an embryo by itself, may be potentially useful to help to find the embryos with the most implantation potential and possibly to identify the most viable embryos from a cohort of euploid embryos. The current situation is that non-invasive methods are promising, but not sufficiently reproducible to replace invasive techniques such as CCS which still remains the most reliable approach to identify chromosomal aneuploidy and thus viability.

\section{Discussion}

\section{What are the prospects for agreement about the clinical benefits of PGT-A?}

The techniques of aCGH, NGS, blastocyst culture and biopsy as well as freeze-all approaches - individually and collectively - have the potential to improve PGT-A. Indeed, there is increasing evidence of its efficacy in improving IVF outcomes and reducing the risk of miscarriage (Yang et al. 2012, Forman et al. 2013b,c, Scott et al. 2013b, Giménez et al. 2015). Prospects for non-invasive PGT-A are constantly being investigated. Nonetheless, the debate of whether we should implement PGT-A at all shows no signs of abating. Numerous reports including meta-analysis and systematic reviews have demonstrated an improvement on implantation, clinical pregnancy, ongoing pregnancy and live birth rates, while reducing miscarriage rate and multiple pregnancy rate through the use of PGT-A, particularly in patients with normal ovarian reserve (Lee et al. 2015, Chen et al. 2015, Dahdouh et al. 2015b). A combination of the findings of 19 articles were summarized including 3 RCTs and 16 observational 
studies which revealed the potential benefits over the traditional method of morphology-based selection of embryos (Lee et al. 2015). Similarly, in a meta-analysis where 4 RCTs and 7 cohort studies were assessed for the effectiveness of CCS-based PGT-A over traditional morphological methods, according to that, the transfer of euploid embryos (blastocyst stage or cleavage stage) can improve the implantation rate (Chen et al. 2015). At the time of writing, there are 2 further RCTs pertaining to PGT-A giving relatively positive support for PGT-A and the more recent STAR (Single Embryo TrAnsfeR of Euploid Embryo) Trial (NCT02268786) not reporting an overall success, but significant improvements in the AMA category. Nonetheless, the debate of whether we should implement PGT-A at all looks set to continue.

Indeed, establishing the efficacy of PGT-A is perhaps not an easy task as it might first appear and we might consider that PGT-A should be assessed on its ability to improve the efficiency of IVF. We can perhaps all accept that the definition of evidence-based medicine (EBM) is 'An approach to medical practice intended to optimize decision making by emphasizing the use of evidence from well designed and conducted research.' The issue arises, however, in defining what 'well-designed' and 'well-conducted' actually mean. This can apply in the context of PGT-A specifically, but also in reproductive medicine in general. Reproductive medicine represents a rare scenario in which patients have radical therapies with an intention that does not necessarily involve benefiting their own health. Indeed, there can be few medical disciplines where so many different academic fields combine and what might be described as barely perceptible 'good gardening' skills are so essential. It is the only medical procedure where the physiologies of two individuals combine (sometimes the two parties do not even meet) and where the sole intention is to produce another human being (Griffin \& Sheldon 2017). It is hardly a controversial statement to say that some centers appear to be better than others in producing viable, euploid embryos for multiple, independent reasons including such diverse factors as the management of the clinic, its policies, its access to technologies, quality management systems, patient demographics and so on (Schoolcraft et al. 2017).

This ultimately then leads to the question of, at what stage do we consider the evidence base good enough to justify PGT-A? One view is that any therapy should only be introduced into the clinic after at least one favorable double-blind RCT and, until that time, any treatment should only be considered 'experimental.' Indeed, this is standard practice for many other areas of medicine. Problems arise, however, with the standard 'pyramid model' for EBM (Tomlin \& Borgetto 2011) when applied to IVF-related procedures. That is, placebos are not usually applicable, the skill of the embryologist (or lack of it) can single-handedly negate any benefit of the treatment (rendering any careful attempts at randomization meaningless) and the question of how genuinely 'blind' studies actually are when we ask do people performing micromanipulation not know they are doing it? Griffin and Sheldon (2017) therefore suggested that, in the context of PGT-A, retrospective, single-center studies may be just as useful to the big picture as randomized trials. Moreover, it is possible that meta-analyses could mask particularly bad (or good) practice by individual clinics.

Within this framework, we therefore need to consider what does the current evidence base for PGT-A actually mean with a critical eye, not automatically assuming that the RCTs are the 'only and ultimate' source of information. Randomization alone does not make a good study. As mentioned earlier, there is a fairly extensive evidence base supporting the efficacy of PGTA. Nonetheless, each study is open to criticism and even the RCTs fall short of 'intent to treat' criteria.

A small but vociferous group of IVF practitioners argue that PGT-A is not properly validated on the basis that we must always wait for the results of randomized trials (with intent to treat analysis) before introducing a new technology (Gleicher et al. 2014, Mastenbroek \& Repping 2014, Orvieto 2016). They argue that current analyses are not sufficiently robust in that they are biased by the fact that clinics are motivated by the need to be seen to be innovating and by the income associated with charging patients for 'the latest' therapy. PGT-A is considered a so-called 'add on' treatment without proper supporting evidence and that any such treatment not validated by RCTs should only be part of a trial.

The counter argument (favored by the majority of the IVF community) is that there is sufficient evidence justifying the continuation of PGT-A and that in reproductive medicine we cannot always wait for randomized trials. This is partly because clinics depend, for their survival and the employment of their staff, on their ability to innovate quickly. The argument goes that innovation is good, and clinics that do not innovate typically have low success rates. The point is made that, for example ICSI and new variants on IVF culture media would never have been introduced if subject to prior rigors of a randomized trial before being licensed. Indeed, when randomized trials are designed, they can take years, they are poorly funded (unlike drug trials) and the benefits of the treatment may already be obvious without an RCT (Griffin \& Sheldon 2017).

In a 'straw man' exercise, Griffin and Sheldon (2017) introduce 'Jacob and Giuseppe' - imaginary individuals designed to represent the extreme sides of the PGT-A argument expressed earlier that seems to be no closer to agreement. In an attempt (perhaps futile) to try and bring the two sides a little closer to agreement, the article argues that RCTs remain the gold standard but just because a study is a randomized trial does not necessarily mean it is a good study - especially if badly performed. Equally, a non-randomized study is not necessarily a bad one. 
They consider the patient perspective: if a couple seeks treatment they may choose a clinic that is dedicated to making that treatment work, not one that has an open mind based on the result of an RCT? A couple would perhaps wish to know the results of that specific clinic, regarding whether a particular treatment works in their hands rather than the results of an RCT. A further consideration from an ethico-legal perspective (Griffin \& Sheldon 2017) is what are the implications of not implementing PGT-A? It is important to consider the harm that could be caused to a patient who has an aneuploid pregnancy, assuming that they could, and would, have chosen to avoid this, had PGT-A been offered to them.

The world has at least moved on as a result of the evidence base over the last 10 years. Cleavage-stage biopsy is now rarely performed even though some trials have shown a benefit (Rubio et al. 2013, 2017). The use of FISH for PGT-A is now widely discontinued and replaced by aCGH or, more recently, NGS, even though some might argue FISH diagnosis can still be effective. Regardless of whether we are a 'Jacob' or a 'Giuseppe,' however, we need not be complacent. We need to learn more, and we need to look more closely at the nature of the mosaic error when we identify it. If we accept that most (if not all) human IVF embryos are mosaic, and the fact that some mosaic conceptuses will proceed uneventfully to term, then more research is needed to identify them. Aneuploid/mosaic embryos that have multiple abnormalities (chaotic) or where the original error arises in meiosis are very unlikely to proceed to term. It is difficult to argue that these should not be screened out by PGT-A. Of the many post-zygotic mosaics that do proceed to term, however, identifying those that would lead to normal live born offspring is more problematic. There is some evidence in the literature already, however: As a single example, trisomy 3 mosaicism is usually only confined to the trophoblastic cells and rarely leads to an adverse outcome (spontaneous abortion) unless $>90 \%$ of the cells are affected (Wolstenholme 1996).

PGT-A thus still remains, at best, a screening tool that gives an indication of the likelihood that the majority of cells of a fetus will be affected with an aneuploidy. Strictly speaking, the chance of detection increases with the more cells that are affected, regardless of any incidence of confined mosaicism. The likelihood of adverse outcomes similarly increases with the number abnormal cells, so overall, even screening out all mosaic embryos should work. Screening out all mosaics (especially where all embryos from a couple are deemed abnormal or mosaic) would be an extremely stringent criterion and consideration should be given to scenarios where mosaicism could lead to viable offspring (mosaic trisomy 3 in the TE is a good example - Wolstenholme 1996). Nonetheless, PGT-A is less likely to be effective in laboratories where post-zygotic aneuploidies are generally high, where pregnancy rates are generally low and certainly in laboratories where biopsy techniques are sub-optimal and damaging the embryo. In other words, a multicenter RCT, including a large number of laboratories of variable quality, would be unlikely to show a benefit of PGT-A.

On balance, therefore, we would argue that PGT-A should continue. The signs are mostly good; it will only improveby practicing it more, and clinics are getting better at it. There is much to improve, however. Karyomapping in combination with NGS could be achieved tomorrow to differentiate meiotic from mitotic errors and we note from the more recent COGEN and PGDIS meetings (personal communication, Santiago Munné group) that some clinics are already implementing it. In addition, new PGD solutions for the simultaneous detection of both aneuploidy and mutations are also currently being developed by many companies using a combination of different techniques. A more sophisticated way of stratifying referral categories is necessary and, as always, improved external quality assessment might ensure that embryo biopsy does not damage the embryo and mosaic embryos can be reliably detected and consistently reported. New technologies, for example blastocentesis, metabolomics, transcriptomics, time lapse may provide non- (or minimally) invasive alternatives to embryo biopsy in the longer term. Furthermore, third-generation sequencing also known as 'single molecule sequencing' or 'nanopore sequencing' (Loose et al. 2017) techniques are promising in the way they might help to overcome the need for WGA which poses an increased risk of technical artifacts related with amplification and could give a better estimation of mosaicism values. In the meantime, perhaps a 'traffic light' system may be appropriate. In such a scenario, all chaotic and meiotic errors, all trisomies 21, 18 and 13 all monosomies and deletions would get a 'red light' and not be transferred. No detected abnormality would get a 'green light' for possible transfer, but an 'amber' category would apply for some post-zygotic trisomies particularly those of low level. These could be referred to a genetic counselor for a case-by-case decision or recommended for a second biopsy. Alternatively, a paradigm shift in the way we consider PGT-A could occur such that embryo transfer is prioritized according to the results obtained rather than the current binary practice of keeping or discarding embryos. In any event, more research is necessary to identify the best approach to improve patient care and minimize harm, in particular taking note of the mechanism through which the mosaicism arose.

\section{Questions that still need answering}

Studies on human embryos provide a window of opportunity to study the cytogenetics of the earliest stages of human development. A deep understanding of meiosis, genetic recombination and molecular biology could then facilitate the improvement of techniques used in PGD and PGT-A. Karyomapping is a good example of how one such technique can be used to address basic biological 
questions (Ottolini et al. 2015). One glaring omission from the scientific literature at the moment, however, is a comprehensive cell-by-cell comparison of a large cohort of blastocyst embryos to establish overall levels of mosaicism in different germ layers (Taylor et al. 2016). In fact, some of this may be estimated from preexisting NGS data; however, the question of level of meiotic vs postzygotic errors would benefit from whole embryo analysis. Taking the research further, we might be able to establish what, if any, approaches can be used to reduce levels of iatrogenic aneuploidy (for instance improved embryo culture (post-zygotic) or improved ovarian stimulation or patient management (that theoretically could affect the incidence of meiotic errors). Through in-depth basic research and comparison with model systems (e.g. mouse, pig, cattle), basic questions not only relevant to PGT-A but also to IVF in general (and to naturally conceived fetuses) could be addressed more deeply. For instance:

- Are patterns of confined mosaicism laid down in the embryo or as a result of differential survival?

- If most embryos have some form of (mosaic) aneuploidy, is this normal?

- Which aneuploid mosaics are least likely to have adverse outcomes?

- Are IVF embryos representative of in vivo fertilized embryos? This may well not be the case. For instance, Hassold and colleagues suggest that meiosis I errors are far more common in live born (non-IVF) individuals and Handyside et al (2012) suggest that MI and MII errors are equally likely. Equally, is precocious chromatid separation a largely IVF-induced phenomenon?

- Do chromosome errors perpetuate further errors in human embryos (akin to an interchromosomal effect)?

- Is there any relevance of the spatio-temporal nuclear organization of chromatin in 4 dimensions and its relationship to gene expression? This is certainly the case in other cell types

- Are there any correlates of chromosome errors that might be detected non-invasively, for example through metabolomics or time lapse? Thus far, these have not been found in any convincing manner but that does not mean they are not there to be found.

And of course, we need more RCTs, some of which stratify patient groups (e.g. comparing AMA vs recurrent implantation failure vs recurrent pregnancy loss vs oligozoospermia). Indeed, in the most recent RCT, the Illumina STAR trial appears to have ammunition for both the 'Jacobs' and the 'Giuseppes.'

\section{Conclusions}

In conclusion, PGT-A is a controversial area of medicine but is probably here to stay, despite the controversy. The opportunity for understanding aneuploidy and mosaicism in IVF and in the general population that consist mostly of natural conceptions must not be missed, and there has never been a more important time than now to perform basic (human and non-human) research in this area. Importantly, however, 'Jacob' and 'Giuseppe' need to talk to one another more and appreciate that patients will benefit by their respectful dialog and compromise (both raise good points) but not by creating an entrenched argument. 'Staged' introduction of protocols for new innovations are essential, appreciating the value of the evidence base as it stands, as is keeping patients 'in the loop' about where the evidence base currently lies and the fact that it is unlikely to ever be as robust as other areas of clinical practice, given the unique nature of reproductive medicine.

We, the authors, would thus like to conclude with this plea: Companies, governments, research councils and charities: please work together to generate more funding for basic research into the chromosomes of human embryos. There are benefits to be had from all sides: For the companies, a large proportion of embryos, even from younger women, are aneuploid and will not develop. Identifying those that will and those that will not may lead to a future where every IVF cycle may involve some variants of PGT-A. For the furtherance of medical research, a greater understanding of aneuploidy and mosaicism generally will lead to improved patient management for many more couples, which with increasingly older families, is one of the most significant genetic problems in reproduction.

\section{Declaration of interest}

The authors declare that there is no conflict of interest that could be perceived as prejudicing the impartiality of this review.

\section{Funding}

This research did not receive any specific grant from any funding agency in the public, commercial or not-for-profit sector.

\section{Acknowledgements}

The authors would like to thank Prof. Alan Thornhill for his critical reading of the manuscript.

\section{References}

Altmäe S, Tamm-Rosenstein K, Esteban FJ, Simm J, Kolberg L, Peterson H, Metsis M, Haldre K, Horcajadas JA, Salumets A et al. 2016 Endometrial transcriptome analysis indicates superiority of natural over artificial cycles in recurrent implantation failure patients undergoing frozen embryo transfer. Reproductive BioMedicine Online 32 597-613. (https:// doi.org/10.1016/j.rbmo.2016.03.004)

Baart EB, Martini E, van den Berg I, Macklon NS, Galjaard RJ, Fauser BC \& VanOpstal D 2006 Preimplantation genetic screening reveals a high incidence of aneuploidy and mosaicism in embryos from young women undergoing IVF. Human Reproduction 21 223-233. (https://doi. org/10.1093/humrep/dei291)

Baart EB, Martini E, Eijkemans MJ, Van Opstal D, Beckers NG, Verhoeff A, Macklon NS \& Fauser BC 2007 Milder ovarian stimulation for in-vitro fertilizationreduces aneuploidy in the human preimplantation embryo: a 
randomized controlledtrial. Human Reproduction 22 980-988. (https:// doi.org/10.1093/humrep/del484)

Basile N, Nogales Mdel C, Bronet F, Florensa M, Riqueiros M, Rodrigo L, García-Velasco J \& Meseguer M 2014 Increasing the probability of selecting chromosomally normal embryos by time-lapse morphokinetics analysis. Fertility and Sterility 101 699-704. (https://doi.org/10.1016/j. fertnstert.2013.12.005)

Benkhalifa M, Kasakyan S, Clement P, Baldi M, Tachdjian G, Demirol A, Gurgan T, Fiorentino F, Mohammed M \& Qumsiyeh MB 2005 Array comparative genomic hybridization profiling of first-trimester spontaneous abortions that fail to grow in vitro. Prenatal Diagnosis 25 894-900. (https://doi.org/10.1002/pd.1230)

Bolton H, Graham SJ, Van der Aa N, Kumar P, Theunis K, Fernandez Gallardo E, Voet T \& Zernicka-Goetz M 2016 Mouse model of chromosome mosaicism reveals lineage-specific depletion of aneuploid cells and normal developmental potential. Nature Communications 29 11165. (https://doi.org/10.1038/ncomms11165)

Brison DR, Houghton FD, Falconer D, Roberts SA, Hawkhead J, Humpherson PG, Lieberman BA \& Leese HJ 2004 Identification of viable embryos in IVF by non-invasive measurement of amino acid turnover. Human Reproduction 19 2319-2324. (https://doi.org/10.1093/ humrep/deh409)

Brown S 2017 Still in highESTEEM. Focus on Reproduction. July 4, The blog of ESHRE's Magazine. (available at: https://focusonreproduction.eu/)

Campbell A, Fishel S, Bowman N, Duffy S, Sedler M \& Hickman CF 2013 a Modelling a risk classification of aneuploidy in human embryos using non-invasive morphokinetics. Reproductive BioMedicine Online $\mathbf{2 6}$ 477-485. (https://doi.org/10.1016/j.rbmo.2013.02.006)

Campbell A, Fishel S, Bowman N, Duffy S, Sedler M \& Thornton S 2013 b Retrospective analysis of outcomes after IVF using an aneuploidy risk model derived from time-lapse imaging without PGS. Reproductive BioMedicine Online 27 140-146. (https://doi.org/10.1016/j. rbmo.2013.04.013)

Capalbo A, Wright G, Elliott T, Ubaldi FM, Rienzi L \& Nagy ZP 2013a FISH reanalysis of inner cell mass and trophectoderm samples of previously array-CGH screened blastocysts shows high accuracy of diagnosis and no major diagnostic impact of mosaicism at the blastocyst stage. Human Reproduction 28 2298-2307. (https://doi.org/10.1093/humrep/det245)

Capalbo A, Bono S, Spizzichino L, Biricik A, Baldi M, Colamaria S, Ubaldi FM, Rienzi L \& Fiorentino F 2013b Sequential comprehensive chromosome analysis on polar bodies, blastomeres and trophoblast: insights into female meiotic errors and chromosomal segregation in the preimplantation window of embryo development. Human Reproduction 28 509-518. (https://doi.org/10.1093/humrep/des394)

Capalbo A, Ubaldi FM, Cimadomo D, Maggiulli R, Patassini C, Dusi L, Sanges F, Buffo L, Venturella R \& Rienzi L 2016 Consistent and reproducible outcomes of blastocyst biopsy and aneuploidy screening across different biopsy practitioners: a multicentre study involving 2586 embryo biopsies. Human Reproduction 31 199-208. (https://doi. org/10.1093/humrep/dev294)

Chavez SL, Loewke KE, Han J, Moussavi F, Colls P, Munné S, Behr B \& Reijo Pera RA 2012 Dynamic blastomere behaviour reflects human embryo ploidy by the four-cell stage. Nature Communications 31251. (https://doi.org/10.1038/ncomms2249)

Chawla M, Fakih M, Shunnar A, Bayram A, Hellani A, Perumal V, Divakaran J \& Budak E 2015 Morphokinetic analysis of cleavage stage embryos and its relationship to aneuploidy in a retrospective time-lapse imaging study. Journal of Assisted Reproduction and Genetics 32 69-75. (https://doi.org/10.1007/s10815-014-0372-3)

Chen M, Song P, Zou D, Hu X, Zhao S, Gao S \& Ling F 2014 Comparison of multiple displacement amplification (MDA) and multiple annealing and looping-based amplification cycles (MALBAC) in single-cell sequencing. PLOS ONE 9 e114520. (https://doi.org/10.1371/journal.pone.0114520)

Chen M, Wei S, Hu J \& Quan S 2015 Can comprehensive chromosome screening technology improve IVF/ICSI outcomes? A meta-analysis. PLoS ONE 10 e0140779. (https://doi.org/10.1371/journal.pone.0140779)

Cimadomo D, Capalbo A, Ubaldi FM, Scarica C, Palagiano A, Canipari R \& Rienzi L 2016 The impact of biopsy on human embryo developmental potential during preimplantation genetic diagnosis. BioMed Research International 2016 10. (https://doi.org/10.1155/2016/7193075)

Coates A, Hurliman A, Hesla J, Coate B, Holmes L, Matthews R \& Griffin DK 2015 Use of suboptimal sperm increases the risk of aneuploidy of the sex chromosomes in preimplantation blastocystembryos. Fertility and Sterility 104 866-872. (https://doi.org/10.1016/j.fertnstert.2015.06.033)

Coates A, Kung A, Mounts E, Hesla J, Bankowski B, Barbieri E, Ata B, Cohen J \& Munné S 2017 Optimal euploid embryo transfer strategy, fresh versus frozen, after preimplantation genetic screening with next generation sequencing: a randomized controlled trial. Fertility and Sterility 107 723-730. (https://doi.org/10.1016/j.fertnstert.2016.12.022)

Cobo A, de los Santos MJ, Castellò D, Gámiz P, Campos P \& Remohí J 2012 Outcomes of vitrified early cleavage-stage and blastocyst-stage embryos in a cryopreservation program: evaluation of 3,150 warming cycles. Fertility and Sterility 98 1138-46. (https://doi.org/10.1016/j. fertnstert.2012.07.1107)

Cohen J, Wells D \& Munné S 2007 Removal of 2 cells from cleavage stage embryos is likely to reduce the efficacy of chromosomal tests that are used to enhance implantation rates. Fertility and Sterility 87 496-503. (https://doi.org/10.1016/j.fertnstert.2006.07.1516)

Coonen E, Derhaag JG, Dumoulin JC, van Wissen LC, Bras M, Janssen M, Evers JL \& Geraedts JP 2004 Anaphase lagging mainly explains chromosomal mosaicism in human preimplantation embryos. Human Reproduction 2 316-324. (https://doi.org/10.1093/humrep/deh077)

Dahdouh EM, Balayla J, Audibert F, Genetics Committee, Wilson RD, Audibert F, Brock JA, Campagnolo C, Carroll J, Chong K et al. 2015a Technical update: preimplantation genetic diagnosis and screening. Journal of Obstetrics and Gynaecology Canada 37 451-463. (https://doi. org/10.1016/S1701-2163(15)30261-9)

Dahdouh EM, Balayla J \& García-Velasco JA 2015b Impact of blastocyst biopsy and comprehensive chromosome screening technology on preimplantation genetic screening: a systematic review of randomized controlled trials. Reproductive BioMedicine Online 30 281-289. (https:// doi.org/10.1016/j.rbmo.2014.11.015)

De Ravel TJ, Devriendt K, Fryns JP \& Vermeesch JR 2007 What's new in karyotyping? The move towards array comparative genomic hybridisation (CGH). European Journal of Pediatrics 166 637-643. (https://doi. org/10.1007/s00431-007-0463-6)

Del Carmen Nogales $M$, Bronet F, Basile N, Martínez EM, Liñán A, Rodrigo L \& Meseguer M 2017 Type of chromosome abnormality affects embryo morphology dynamics. Fertility and Sterility 107 229-235. (https://doi.org/10.1016/j.fertnstert.2016.09.019)

Deleye L, De Coninck D, Christodoulou C, Sante T, Dheedene A, Heindryckx B, Van den Abbeel E, De Sutter P, Menten B, Deforce D et al. 2015 Whole genome amplification with SurePlex results in better copy number alteration detection using sequencing data compared to the MALBAC method. Scientific Reports 30 11711. (https://doi. org/10.1038/srep11711)

Delhanty JD, Griffin DK, Handyside AH, Harper J, Atkinson GH, Pieters MH \& Winston RM 1993 Detection of aneuploidy and chromosomal mosaicism in human embryos during preimplantation sex determination by fluorescent in situ hybridisation, (FISH). Human Molecular Genetics 2 1183-1185. (https://doi.org/10.1093/hmg/2.8.1183)

Dieamant FC, Petersen CG, Mauri AL, Comar V, Mattila M, Vagnini LD, Renzi A, Petersen B, Nicoletti A, Oliveira JBA et al. 2017 Fresh embryos versus freeze-all embryos - transfer strategies: nuances of a metaanalysis. JBRA Assisted Reproduction 21 260-272.

Diez-Juan A, Rubio C, Marin C, Martinez S, Al-Asmar N, Riboldi M, DíazGimeno P, Valbuena D \& Simón C 2015 Mitochondrial DNA content as a viability score in human euploid embryos: less is better. Fertility and Sterility 104 534-541. (https://doi.org/10.1016/j.fertnstert.2015.05.022)

Duncan FE, Stein P, Williams CJ \& Schultz RM 2009 The effect of blastomere biopsy on preimplantation mouse embryo development and global gene expression. Fertility and Sterility 91 1462-1465. (https://doi. org/10.1016/j.fertnstert.2008.07.1710)

Edwards RG \& Gardner RL 1967 Sexing of live rabbit blastocysts. Nature 214 576-577. (https://doi.org/10.1038/214576a0)

Eichenlaub-Ritter U, Vogt E, Yin H \& Gosden R 2004 Spindles, mitochondria and redoxpotential in ageing oocytes. Reproductive BioMedicine Online 8 45-58. (https://doi.org/10.1016/S1472-6483(10)60497-X)

Evsikov S \& Verlinsky Y 1998 Mosaicism in the inner cell mass of human blastocysts. Human Reproduction 13 3151-3155. (https://doi. org/10.1093/humrep/13.11.3151)

Feichtinger M, Stopp T, Göbl C, Feichtinger E, Vaccari E, Mädel U, Laccone $F$, Stroh-Weigert $M$, Hengstschläger $M$, Feichtinger $W$ et al. 2015 Increasing live birth rate by preimplantation genetic screening of 
pooled polar bodies using array comparative genomic hybridization. PLoS ONE 10 e0128317. (https://doi.org/10.1371/journal.pone.0128317)

Feichtinger M, Vaccari E, Carli L, Wallner E, Mädel U, Figl K, Palini S \& Feichtinger W 2017 Non-invasive preimplantation genetic screening using array comparative genomic hybridization on spent culture media: a proof-of-concept pilot study. Reproductive BioMedicine Online 34 583-589. (https://doi.org/10.1016/j.rbmo.2017.03.015)

Fishel S, Gordon A, Lynch C, Dowell K, Ndukwe G, Kelada E, Thornton S, Jenner L, Cater E, Brown A et al. 2010 Live birth after polar body array comparative genomic hybridization prediction of embryo ploidy-the future of IVF? Fertility and Sterility 931006.

Findikli N, Kahraman S, Saglam Y, Beyazyurek C, Sertyel S, Karlikaya G, Karagozoglu H \& Aygun B 2006 Embryo aneuploidy screening for repeated implantation failure and unexplained recurrent miscarriage. Reproductive BioMedicine Online 13 38-46. (https://doi.org/10.1016/ S1472-6483(10)62014-7)

Fiorentino F, Spizzichino L, Bono S, Biricik A, Kokkali G, Rienzi L, Ubaldi FM, lammarrone E, Gordon A \& Pantos K 2011 PGD for reciprocal and Robertsonian translocations using array comparative genomic hybridization. Human Reproduction 26 1925-1935. (https:// doi.org/10.1093/humrep/der082)

Fiorentino F, Biricik A, Bono S, Spizzichino L, Cotroneo E, Cottone G, Kokocinski F \& Michel CE 2014 Development and validation of a nextgeneration sequencing-based protocol for 24-chromosome aneuploidy screening of embryos. Fertility and Sterility 101 1375-1382. (https://doi. org/10.1016/j.fertnstert.2014.01.051)

Forman EJ, Ferry KM, Gueye NA, Smith RD, Stevens J \& Scott RT Jr 2011 Trophectoderm biopsy for single-gene disorder preimplantation genetic diagnosis (PGD) is significantly more reliable than day 3 blastomere biopsy. Fertility and Sterility 96 S222. (https://doi.org/10.1016/j. fertnstert.2011.07.853)

Forman EJ, Treff NR, Stevens JM, Garnsey HM, Katz-Jaffe MG, Scott RT Jr \& Schoolcraft WB 2013a Embryos whose polar bodies contain isolated reciprocal chromosome aneuploidy are almost always euploid. Human Reproduction 28 502-508. (https://doi.org/10.1093/humrep/des393)

Forman EJ, Hong KH, Ferry KM, Tao X, Taylor D, Levy B, Treff NR \& Scott RT Jr 2013b In vitro fertilization with single euploid blastocyst transfer: a randomized controlled trial. Fertility and Sterility $\mathbf{1 0 0}$ 100-107. (https://doi.org/10.1016/j.fertnstert.2013.02.056)

Forman EJ, Upham KM, Cheng M, Zhao T, Hong KH, Treff NR \& Scott RT Jr 2013c Comprehensive chromosome screening alters traditional morphology-based embryo selection: a prospective study of 100 consecutive cycles of planned fresh euploid blastocyst transfer. Fertility and Sterility 100 718-724. (https://doi.org/10.1016/j. fertnstert.2013.04.043)

Forozan F, Karhu R, Kononen J, Kallioniemi A \& Kallioniemi OP 1997 Genome screening by comparative genomic hybridization. Trends in Genetics 13 405-409. (https://doi.org/10.1016/S01689525(97)01244-4)

Fragouli E \& Wells D 2011 Aneuploidy in the human blastocyst. Cytogenetic and Genome Research 133 149-159. (https://doi. org/10.1159/000323500)

Fragouli E, Lenzi M, Ross R, Katz-Jaffe M, Schoolcraft WB \& Wells D 2008 Comprehensive molecular cytogenetic analysis of the human blastocyst stage. Human Reproduction 23 2596-2608. (https://doi.org/10.1093/ humrep/den287)

Fragouli E, Alfarawati S, Daphnis DD, Goodall NN, Mania A, Griffths T, Gordon A \& Wells D 2011 Cytogenetic analysis of human blastocysts with the use of FISH, CGH and aCGH: scientific data and technical evaluation. Human Reproduction 26 480-490. (https://doi.org/10.1093/ humrep/deq344)

Fragouli E, Spath K, Alfarawati S, Kaper F, Craig A, Michel CE, Kokocinski F, Cohen J, Munné S \& Wells D 2015 Altered levels of mitochondrial DNA are associated with female age, aneuploidy, and provide an independent measure of embryonic implantation potential. PLOS Genetics 11 e1005241. (https://doi.org/10.1371/journal.pgen.1005241)

Fragouli E, Alfarawati S, Spath K, Babariya D, Tarozzi N, Borini A \& Wells D 2017 Analysis of implantation and ongoing pregnancy rates following the transfer of mosaic diploid-aneuploid blastocysts. Human Genetics 136 805-819. (https://doi.org/10.1007/s00439-017-1797-4)

Franasiak JM, Forman EJ, Hong KH, Werner MD, Upham KM, Treff NR \& Scott RT Jr 2014 The nature of aneuploidy with increasing age of the female partner: a review of 15,169 consecutive trophectoderm biopsies evaluated with comprehensive chromosomal screening. Fertility and Sterility 101 656-663. (https://doi.org/10.1016/j.fertnstert.2013.11.004)

Geraedts J, Collins J, Gianaroli L, Goossens V, Handyside A, Harper J, Montag M, Repping S \& Schmutzler A 2010 What next for preimplantation genetic screening? A polar body approach! Human Reproduction 25 575-577.

Geraedts J, Montag M, Magli MC, Repping S, Handyside A, Staessen C, Harper J, Schmutzler A, Collins J \& Goossens V 2011 Polar body aCGH for prediction of the status of the corresponding oocyte. Part I: clinical results. Human Reproduction 26 3173-3180. (https://doi.org/10.1093/ humrep/der294)

Gianaroli L, Magli MC, Ferraretti AP, Tabanelli C, Trengia V, Farfalli V \& Cavallini G 2005 The beneficial effects of preimplantation genetic diagnosis for aneuploidy support extensive clinical application. Reproductive BioMedicine Online 10 633-640. (https://doi.org/10.1016/ S1472-6483(10)61671-9)

Gianaroli L, Magli MC, Pomante A, Crivello AM, Cafueri G, Valerio M \& Ferraretti AP 2014 Blastocentesis: a source of DNA for preimplantation genetic testing. Results from a pilot study. Fertility and Sterility 102 1692-1699. (https://doi.org/10.1016/j.fertnstert.2014.08.021)

Giménez C, Sarasa J, Arjona C, Vilamajó E, Martínez-Pasarell O, Wheeler K, Valls G, Garcia-Guixé E \& Wells D 2015 Karyomapping allows preimplantation genetic diagnosis of a de-novo deletion undetectable using conventional PGD technology. Reproductive BioMedicine Online $31770-775$.

Gleicher N, Kushnir VA \& Barad DH 2014 Preimplantation genetic screening (PGS) still in search of a clinical application: a systematic review. Reproductive Biology and Endocrinology 12 22. (https://doi. org/10.1186/1477-7827-12-22)

Goodrich D, Tao X, Bohrer C, Lonczak A, Xing T, Zimmerman R, Zhan Y, Scott RT Jr \& Treff NR 2016 A randomized and blinded comparison of qPCR and NGS-based detection of aneuploidy in a cell line mixture model of blastocyst biopsy mosaicism. Journal of Assisted Reproduction and Genetics 33 1473-1480. (https://doi.org/10.1007/s10815-0160784-3)

Greco E, Minasi MG \& Fiorentino F 2015 Healthy babies after intrauterine transfer of mosaic aneuploid blastocysts. New England Journal of Medicine 373 2089-2090. (https://doi.org/10.1056/NEJMc1500421)

Griffin DK \& Sheldon S 2017 PGS in the clinic 'Jacob' vs 'Giuseppe'. Focus on Reproduction 22-26.

Griffin DK, Wilton LJ, Handyside AH, Winston RM \& Delhanty JD 1992 Dual fluorescent in situ hybridisation for simultaneous detection of $\mathrm{X}$ and Y chromosome-specific probes for the sexing of human preimplantation embryonic nuclei. Human Genetics 89 18-22. (https://doi.org/10.1007/ BF00207035)

Griffin DK, Wilton LJ, Handyside AH, Atkinson GH, Winston RM \& Delhanty JD 1993 Diagnosis of sex in preimplantation embryos by fluorescent in situ hybridisation. BM/ 306 1382. (https://doi.org/10.1136/ bmj.306.6889.1382)

Griffin DK, Millie EA, Redline RW, Hassold TJ \& Zaragoza MV 1997 Cytogenetic analysis of spontaneous abortions: comparison of techniques and assessment of the incidence of confined placental mosaicism. American Journal of Medical Genetics 72 297-301. (https://doi.org/10.1002/(SICI)1096-8628(19971031)72:3<297::AIDAJMG9>3.0.CO;2-O)

Hammond ER, Shelling AN \& Cree LM 2016 Nuclear and mitochondrial DNA in blastocoele fluid and embryo culture medium: evidence and potential clinical use. Human Reproduction 31 1653-1661. (https://doi. org/10.1093/humrep/dew132)

Handyside AH 2012 Molecular origin of female meiotic aneuploidies. Biochimica et Biophysica Acta 1822 1913-1920. (https://doi. org/10.1016/j.bbadis.2012.07.007)

Handyside AH 2015 Live births following karyomapping - a 'key' milestone in the development of preimplantation genetic diagnosis. Reproductive BioMedicine Online $31 \quad 307-308 . \quad$ (https://doi.org/10.1016/j. rbmo.2015.07.003)

Handyside AH, Kontogianni EH, Hardy K \& Winston RML 1990 Pregnancies from biopsied human preimplantation embryos sexed by Y-specific DNA amplification. Nature 344 768-770. (https://doi.org/10.1038/344768a0) Handyside AH, Lesko JG, Tarín JJ, Winston RM \& Hughes MR 1992 Birth of a normal girl after in vitro fertilization and preimplantation diagnostic 
testing for cystic fibrosis. New England Journal of Medicine $\mathbf{3 2 7}$ 905-909. (https://doi.org/10.1056/NEJM199209243271301)

Handyside AH, Harton GL, Mariani B, Thornhill AR, Affara N, Shaw MA \& Griffin DK 2010 Karyomapping: a universal method for genome wide analysis of genetic disease based on mapping crossovers between parental haplotypes. Journal of Medical Genetics 47 651-658. (https:// doi.org/10.1136/jmg.2009.069971)

Hardarson T, Hanson C, Lundin K, Hillensjo T, Nilsson L, Stevic J, Reismer E, Borg K, Wikland M \& Bergh C 2008 Preimplantation genetic screening in women of advanced maternal age caused a decrease in clinical pregnancy rate: a randomized controlled trial. Human Reproduction 23 2806-2812. (https://doi.org/10.1093/humrep/den217)

Harper JC, Wilton L, Traeger-Synodinos J, Goossens V, Moutou C, SenGupta SB, Pehlivan Budak T, Renwick P, De Rycke M, Geraedts JP et al. 2012 The ESHRE PGD Consortium: 10 years of data collection. Human Reproduction Update 18 234-247. (https://doi.org/10.1093/ humupd/dmr052)

Harton GL, Cinnioglu C \& Fiorentino F 2017 Current experience concerning mosaic embryos diagnosed during preimplantation genetic screening. Fertility and Sterility 107 1113-1119. (https://doi. org/10.1016/j.fertnstert.2017.03.016)

Hassold T \& Hunt P 2001 To err (meiotically) is human: the genesis of human aneuploidy. Nature Reviews Genetics 2 280-291. (https://doi. org/10.1038/35066065)

Haverfield J, Dean NL, Nöel D, Rémillard-Labrosse G, Paradis V, Kadoch IJ \& FitzHarris G 2017 Tri-directional anaphases as a novel chromosome segregation defect in human oocytes. Human Reproduction 32 1293-1303. (https://doi.org/10.1093/humrep/dex083)

Hodes-Wertz B, Grifo J, Ghadir S, Kaplan B, Laskin CA, Glassner M \& Munné S 2012 Idiopathic recurrent miscarriage is caused mostly by aneuploid embryos. Fertility and Sterility 98 675-680. (https://doi. org/10.1016/j.fertnstert.2012.05.025)

Holubcová Z, Blayney M, Elder K \& Schuh M 2015 Human oocytes. Errorprone chromosome-mediated spindle assembly favors chromosome segregation defects in human oocytes. Science 348 1143-1147.

Houghton FD, Hawkhead JA, Humpherson PG, Hogg JE, Balen AH, Rutherford AJ \& Leese HJ 2002 Non-invasive amino acid turnover predicts human embryo developmental capacity. Human Reproduction 17 999-1005. (https://doi.org/10.1093/humrep/17.4.999)

Ioannou D, Meershoek EJ, Thornhill AR, Ballsackz BJ, Ellis M \& Griffin DK 2011 Multicolour interphase cytogenetics: 24 chromosome probes, 6 colours, 4 layers. Molecular and Cellular Probes 25 199-205. (https:// doi.org/10.1016/j.mcp.2011.08.002)

Ioannou D, Fonseka KG, Meershoek EJ, Thornhill AR, Abogrein A, Ellis M \& Griffin DK 2012 Twenty-four chromosome FISH in human IVF embryos reveals patterns of post-zygotic chromosome segregation and nuclear organization. Chromosome Research 20 447-460. (https://doi. org/10.1007/s10577-012-9294-z)

Johnson DS, Gemelos G, Baner J, Ryan A, Cinnioglu C, Banjevic M, Ross R, Alper M, Barrett B, Frederick J et al. 2010a Preclinical validation of a microarray method for full molecular karyotyping of blastomeres in a 24-hprotocol. Human Reproduction 25 1066-1075. (https://doi. org/10.1093/humrep/dep452)

Johnson DS, Cinnioglu C, Ross R, Filby A, Gemelos G, Hill M, Ryan A, Smotrich D, Rabinowitz M \& Murray MJ 2010 b Comprehensive analysis of karyotypic mosaicism between trophectoderm and inner cell mass. Molecular Human Reproduction 16 944-949. (https://doi.org/10.1093/ molehr/gaq062)

Kahraman S, Findikli N, Biricik A, Oncu N, Ogur C, Sertyel S, Karlikaya G, Karagozoglu H \& Saglam Y 2006 Preliminary FISH studies on spermatozoa and embryos in patients with variable degrees of teratozoospermia and a history of poor prognosis. Reproductive BioMedicine Online 12 752-761. (https://doi.org/10.1016/S1472-6483(10)61087-5)

Kahraman S, Beyazyurek C, Yesilipek MA, Ozturk G, Ertem M, Anak S, Kansoy S, Aksoylar S, Kuşkonmaz B \& Oniz H 2014 Successful haematopoietic stem cell transplantation in 44 children from healthy siblings conceived after preimplantation HLA matching. Reproductive BioMedicine Online $29 \quad 340-351 . \quad$ (https://doi.org/10.1016/j. rbmo.2014.05.010)

Kallioniemi A, Kallioniemi OP, Sudar D, Rutovitz D, Gray JW, Waldman F \& Pinkel D 1992 Comparative genomic hybridization for molecular cytogenetic analysis of solid tumors. Science 258 818-821. (https://doi. org/10.1126/science.1359641)

Keltz MD, Vega M, Sirota I, Lederman M, Moshier EL, Gonzales E \& Stein D 2013 Preimplantation genetic screening (PGS) with comparative genomic hybridization $(\mathrm{CGH})$ following day 3 single cell blastomere biopsy markedly improves IVF outcomes while lowering multiple pregnancies and miscarriages. Journal of Assisted Reproduction and Genetics 30 1333-1339. (https://doi.org/10.1007/s10815-013-0070-6)

Kirkegaard K, Hindkjaer J \& Ingerslev HJ 2012 Human embryonic development after blastomere removal: a time-lapse analysis. Human Reproduction 27 97-105. (https://doi.org/10.1093/humrep/der382)

Kirchhoff M, Gerdes T, Rose H, Maahr J, Ottesen AM \& Lundsteen C 1998 Detection of chromosomal gains and losses in comparative genomic hybridization analysis based on standard reference intervals. Cytometry $31 \quad 163-173 . \quad$ (https://doi.org/10.1002/(SICl)10970320(19980301)31:3<163::AID-CYTO3>3.0.CO;2-M)

Knapp M, Stiller M \& Meyer M 2012 Generating barcoded libraries for multiplex high-throughput sequencing. Methods in Molecular Biology 840 155-170.

Kokkali G, Traeger-Synodinos J, Vrettou C, Stavrou D, Jones GM, Cram DS, Makrakis E, Trounson AO, Kanavakis E \& Pantos K 2007 Blastocyst biopsy versus cleavage stage biopsy and blastocyst transfer for preimplantation genetic diagnosis of beta-thalassaemia: a pilot study. Human Reproduction 22 1443-1449. (https://doi.org/10.1093/humrep/ del506)

Koot YE, van Hooff SR, Boomsma CM, van Leenen D, Groot Koerkamp MJ, Goddijn M, Eijkemans MJ, Fauser BC, Holstege FC \& Macklon NS 2016 An endometrial gene expression signature accurately predicts recurrent implantation failure after IVF. Scientific Reports 6 19411. (https://doi. org/10.1038/srep19411)

Kort DH, Chia G, Treff NR, Tanaka AJ, Xing T, Vensand LB, Micucci S, Prosser R, Lobo RA, Sauer MV et al. 2016 Human embryos commonly form abnormal nuclei during development: a mechanism of DNA damage, embryonic aneuploidy, and developmental arrest. Human Reproduction 31 312-323.

Lai HH, Chuang TH, Wong LK, Lee MJ, Hsieh CL, Wang HL \& Chen SU 2017 Identification of mosaic and segmental aneuploidies by nextgeneration sequencing in preimplantation genetic screening can improve clinical outcomes compared to array-comparative genomic hybridization. Molecular Cytogenetics 10 14. (https://doi.org/10.1186/ s13039-017-0315-7)

LaFramboise T 2009 Single nucleotide polymorphism arrays: a decade of biological, computational and technological advances. Nucleic Acids Research 37 4181-4193. (https://doi.org/10.1093/nar/gkp552)

Le Caignec C, Spits C, Sermon K, De Rycke M, Thienpont B, Debrock S, Staessen C, Moreau Y, Fryns JP, Van Steirteghem A et al. 2006 Singlecell chromosomal imbalances detection by array $\mathrm{CGH}$. Nucleic Acids Research 34 e68. (https://doi.org/10.1093/nar/gkl336)

Ledbetter DH, Zachary JM, Simpson JL, Golbus MS, Pergament E, Jackson L, Mahoney MJ, Desnick RJ, Schulman J, Copeland KL et al. 1992 Cytogenetic results from the US collaborative study on CVS. Prenatal Diagnosis 12 317-345.

Lee E, Illingworth P, Wilton L \& Chambers GM 2015 The clinical effectiveness of preimplantation genetic diagnosis for aneuploidy in all 24 chromosomes (PGD-A): systematic review. Human Reproduction 30 473-483. (https://doi.org/10.1093/humrep/deu303)

Leese HJ 2002 Quiet please, do not disturb: a hypothesis of embryo metabolism and viability. Bioessays 24 845-849. (https://doi. org/10.1002/bies.10137)

Li W, Ma Y, Yu S, Sun N, Wang L, Chen D, Yang G, Lu S, Li Y, Yang B et al. 2017 The mutation-free embryo for in vitro fertilization selected by MALBAC-PCD resulted in a healthy live birth from a family carrying PKD 1 mutation. Journal of Assisted Reproduction and Genetics 34 1653-1658.

Lichter P, Joos S, Bentz M \& Lampel S 2000 Comparative genomic hybridization: uses and limitations. Seminars in Hematology 37 348-357. (https://doi.org/10.1016/S0037-1963(00)90015-5)

Lightfoot DA, Kouznetsova A, Mahdy E, Wilbertz J \& Höög C 2006 The fate of mosaic aneuploid embryos during mouse development. Developmental Biology 289 384-394. (https://doi.org/10.1016/j. ydbio.2005.11.001) 
Liu J, Wang W, Sun X, Liu L, Jin H, Li M, Witz C, Williams D, Griffith J, Skorupski J et al. 2012 DNA microarray reveals that high proportions of human blastocysts from women of advanced maternal age are aneuploid and mosaic. Biology of Reproduction 87 148. (https://doi.org/10.1093/ biolreprod/87.s1.148)

Liu W, Liu J, Du H, Ling J, Sun X \& Chen D 2017 Non-invasive preimplantation aneuploidy screening and diagnosis of beta thalassemia IVSII 654 mutation using spent embryo culture medium. Annals of Medicine 49 319-328. (https://doi.org/10.1080/07853890.2016.12548 16)

Liu W, Zhang H, Hu D, Lu S \& Sun X 2018 The performance of MALBAC and MDA methods in the identification of concurrent mutations and aneuploidy screening to diagnose beta-thalassaemia disorders at the single- and multiple-cell levels. Journal of Clinical Laboratory Analysis 32. (https://doi.org/10.1002/jcla.22267)

Loose MW 2017 The potential impact of nanopore sequencing on human genetics. Human Molecular Genetics 26 R202-R207. (https://doi. org $/ 10.1093 / \mathrm{hmg} / \mathrm{dd} \times 287$ )

Magli MC, Montag M, Köster M, Muzi L, Geraedts J, Collins J, Goossens V, Handyside AH, Harper J, Repping S et al. 2011 Polarbody aCGH for prediction of the status of the corresponding oocyte. Part II:technical aspects. Human Reproduction 26 3181-3185. (https://doi.org/10.1093/ humrep/der295)

Magli MC, Pomante A, Cafueri G, Valerio M, Crippa A, Ferraretti AP \& Gianaroli L 2016 Preimplantation genetic testing: polar bodies, blastomeres, trophectoderm cells, or blastocoelic fluid? Fertility and Sterility 105 676-683. (https://doi.org/10.1016/j.fertnstert.2015.11.018)

Mahajan N 2015 Endometrial receptivity array: clinical application. Journal of Human Reproductive Sciences 8 121-129. (https://doi. org/10.4103/0974-1208.165153)

Mamas T, Gordon A, Brown A, Harper J \& Sengupta S 2012 Detection of aneuploidy by array comparative genomic hybridization using cell lines to mimic a mosaic trophectoderm biopsy. Fertility and Sterility $\mathbf{9 7}$ 943-947. (https://doi.org/10.1016/j.fertnstert.2011.12.048)

Mastenbroek S \& Repping S 2014 Preimplantation genetic screening: back to the future. Human Reproduction 29 1846-1850. (https://doi. org/10.1093/humrep/deu163)

Mastenbroek S, Twisk M, van Echten-Arends J, Sikkema-Raddatz B, Korevaar JC, Verhoeve HR, Vogel NE, Arts EG, de Vries JW, Bossuyt PM et al. 2007 In vitro fertilization with preimplantation genetic screening. New England Journal of Medicine 357 9-17. (https://doi.org/10.1056/ NEJMoa067744)

Maxwell SM, Colls P, Hodes-Wertz B, McCulloh DH, McCaffrey C, Wells D, Munné S \& Grifo JA 2016 Why do euploid embryos miscarry? A case-control study comparing the rate of aneuploidy within presumed euploid embryos that resulted in miscarriage or live birth using nextgeneration sequencing. Fertility and Sterility 106 1414-1419. (https:// doi.org/10.1016/j.fertnstert.2016.08.017)

McArthur SJ, Leigh D, Marshall JT, de Boer KA \& Jansen RP 2005 Pregnancies and live births after trophectoderm biopsy and preimplantation genetic testing of human blastocysts. Fertility and Sterility 84 1628-1636. (https:// doi.org/10.1016/j.fertnstert.2005.05.063)

McCoy RC, Demko Z, Ryan A, Banjevic M, Hill M, Sigurjonsson S, Rabinowitz M, Fraser HB \& Petrov DA 2015 Common variants spanning PLK4 are associated with mitotic-origin aneuploidy in human embryos. Science 348 235-238. (https://doi.org/10.1126/science.aaa3337)

Mertzanidou A, Wilton L, Cheng J, Spits C, Vanneste E, Moreau Y, Vermeesch JR \& Sermon K 2013 Microarray analysis reveals abnormal chromosomal complements in over $70 \%$ of 14 normally developing human embryos. Human Reproduction 28 256-264. (https://doi. org/10.1093/humrep/des362)

Meseguer M, Herrero J, Tejera A, Hilligsøe KM, Ramsing NB \& Remohí J 2011 The use of morphokinetics as a predictor of embryo implantation. Human Reproduction 26 2658-2671. (https://doi.org/10.1093/humrep/ der256)

Monnot S, Samuels DC, Hesters L, Frydman N, Gigarel N, Burlet P, Kerbrat V, Lamazou F, Frydman R, Benachi A et al. 2013 Mutation dependance of the mitochondrial DNA copy number in the first stages of human embryogenesis. Human Molecular Genetics 22 1867-1872.

Munné S 2005 Analysis of chromosome segregation during preimplantation genetic diagnosis in both male and female translocation heterozygotes. Cytogenetic and Genome Research 111 305-309.
Munné S \& Wells D 2017 Detection of mosaicism at blastocyst stage with the use of high-resolution next-generation sequencing. Fertility and Sterility 107 1085-1091. (https://doi.org/10.1016/j.fertnstert.2017.05.002)

Munné S, Lee A, Rosenwaks Z, Grifo J \& Cohen J 1993 Diagnosis of major chromosome aneuploidies in human preimplantation embryos. Human Reproduction 8 2185-2191.

Munné S, Weier HU, Grifo J \& Cohen J 1994 Chromosome mosaicism in human embryos. Biology of Reproduction 51 373-379.

Munné S, Ary J, Zouves C, Escudero T, Barnes F, Cinnioglu C, Ary B \& Cohen J 2006 Wide range of chromosome abnormalities in the embryos of young egg donors. Reproductive BioMedicine Online 12 340-346.

Munné S, Fragouli E, Colls P, Katz-Jaffe M, Schoolcraft W \& Wells D 2010 Improved detection of aneuploid blastocysts using a new 12-chromosome FISH test. Reproductive BioMedicine Online 20 92-97.

Munné S, Blazek J, Large M, Martinez-Ortiz PA, Nisson H, Liu E, Tarozzi N, Borini A, Becker A, Zhang J et al. 2017 Detailed investigation into the cytogenetic constitution and pregnancy outcome of replacing mosaic blastocysts detected with the use of high-resolution next-generation sequencing. Fertility and Sterility 108 62-71. (https://doi.org/10.1016/j. fertnstert.2017.05.002)

Natesan SA, Bladon AJ, Coskun S, Qubbaj W, Prates R, Munné S, Coonen E, Dreesen JC, Stevens SJ, Paulussen AD et al. 2014a Genomewide karyomapping accurately identifies the inheritance of single-gene defects in human preimplantation embryos in vitro. Genetics in Medicine 16 838-845. (https://doi.org/10.1038/gim.2014.45)

Natesan SA, Handyside AH, Thornhill AR, Ottolini CS, Sage K, Summers MC, Konstantinidis M, Wells D \& Griffin DK 2014b Live birth after PGD with confirmation by a comprehensive approach (karyomapping) for simultaneous detection of monogenic and chromosomal disorders. Reproductive BioMedicine Online 29 600-605. (https://doi.org/10.1016/j.rbmo.2014.07.007)

Northrop LE, Treff NR, Levy B \& Scott RT Jr 2010 SNP microarray-based 24 chromosome aneuploidy screening demonstrates that cleavagestage FISH poorly predicts aneuploidy in embryos that develop to morphologically normal blastocysts. Molecular Human Reproduction 16 590-600. (https://doi.org/10.1093/molehr/gaq037)

Ogur C, Gultomruk M, Caferler J, Capar B, Findikli N \& Bahceci M 2017 Maternal age has no influence on mitochondrial DNA (mtDNA) content in chromosomally normal embryos. OC-21 Reproductive BioMedicine Online 36 (Supplement 1) e17. (https://doi.org/10.1016/j.rbmo.2017.10.040)

Orvieto R 2016 Preimplantation genetic screening- the required RCT that has not yet been carried out. Reproductive Biology and Endocrinology 14 35. (https://doi.org/10.1186/s12958-016-0171-z)

Ottolini C, Rienzi L \& Capalbo A 2014 A cautionary note against embryo aneuploidy risk assessment using time-lapse imaging. Reproductive BioMedicine Online 28 273-275. (https://doi.org/10.1016/j. rbmo.2013.10.015)

Ottolini CS, Rogers S, Sage K, Summers MC, Capalbo A, Griffin DK, Sarasa J, Wells D \& Handyside AH 2015 Karyomapping identifies second polar body DNA persisting to the blastocyst stage: implications for embryo biopsy. Reproductive BioMedicine Online 31 776-782. (https://doi.org/10.1016/j.rbmo.2015.07.005)

Palermo GD, Colombero LT \& Rosenwaks Z 1997 The human sperm centrosome is responsible for normal syngamy and early embryonic development. Reviews of Reproduction 2 19-27. (https://doi. org/10.1530/ror.0.0020019)

Patel DV, Shah PB, Kotdawala AP, Herrero J, Rubio I \& Banker MR 2016 Morphokinetic behavior of euploid and aneuploid embryos analyzed by time-lapse in embryoscope. Journal of Human Reproductive Sciences 9 112-118. (https://doi.org/10.4103/0974-1208.183511)

Penrose LS 1933 The relative effect of paternal and maternal age in Mongolism. Journal of Genetics 27 219-224. (https://doi.org/10.1007/ BF02984413)

Rabinowitz M, Ryan A, Gemelos G, Hill M, Baner J, Cinnioglu C, Banjevic M, Potter D, Petrov DA \& Demko Z 2012 Origins and rates of aneuploidy in human blastomeres. Fertility and Sterility 97 395-401. (https://doi.org/10.1016/j.fertnstert.2011.11.034)

Ravichandran K, McCaffrey C, Grifo J, Morales A, Perloe M, Munné S, Wells D \& Fragouli E 2017 Mitochondrial DNA quantification as a tool for embryo viability assessment: retrospective analysis of data from single euploid blastocyst transfers. Human Reproduction 32 1282-1292. (https://doi.org/10.1093/humrep/dex070) 
Robinson WP 2000 Mechanisms leading to uniparental disomy and their clinical consequences. Bioessays 22 452-459. (https://doi.org/10.1002/ (SICI)1521-1878(200005)22:5<452::AID-BIES7>3.0.CO;2-K)

Roy TK, Bradley CK, Bowman MC \& McArthur SJ 2014 Single-embryo transfer of vitrified-warmed blastocysts yields equivalent live-birth rates and improved neonatal outcomes compared with fresh transfers. Fertility and Sterility 101 1294-1301. (https://doi.org/10.1016/j. fertnstert.2014.01.046)

Rubio C, Bellver J, Rodrigo L, Bosch E, Mercader A, Vidal C, De los Santos MJ, Giles J, Labarta E, Domingo J et al. 2013 Preimplantation genetic screening using fluorescence in situ hybridization in patients with repetitive implantation failure andadvanced maternal age:tworandomized trials. Fertility and Sterility 99 1400-1407.

Rubio C, Bellver J, Rodrigo L, Castillón G, Guillén A, Vidal C, Giles J, Ferrando M, Cabanillas S, Remohí J et al. 2017 Invitro fertilization with preimplantation genetic diagnosis for aneuploidies in advanced maternal age: a randomized, controlled study. Fertility and Sterility 107 1122-1129. (https://doi.org/10.1016/j.fertnstert.2017.03.011)

Sachdev NM, Maxwell SM, Besser AG \& Grifo JA 2017 Diagnosis and clinical management of embryonic mosaicism. Fertility and Sterility 107 6-11. (https://doi.org/10.1016/j.fertnstert.2016.10.006)

Salvaggio CN, Forman EJ, Garnsey HM, Treff NR \& Scott RT Jr 2014 Polar body based aneuploidy screening is poorly predictive of embryo ploidy and reproductive potential. Journal of Assisted Reproduction and Genetics 31 1221-1226. (https://doi.org/10.1007/s10815-014-0293-1)

Santos MA, Teklenburg G, Macklon NS, Van Opstal D, Schuring-Blom GH, Krijtenburg PJ, de Vreeden-Elbertse J, Fauser BC \& Baart EB 2010 The fate of the mosaic embryo: chromosomal constitution and development of Day 4, 5 and 8 human embryos. Human Reproduction 25 1916-1926. (https://doi.org/10.1093/humrep/deq139)

Schoolcraft WB, Katz-Jaffe MG, Stevens J, Rawlins M \& Munné S 2009 Preimplantation aneuploidy testing for infertile patients of advanced maternal age: a randomized prospective trial. Fertility and Sterility 92 157-162. (https://doi.org/10.1016/j.fertnstert.2008.05.029)

Schoolcraft W, Meseguer M \& Global Fertility Alliance 2017 Paving the way for a gold standard of care for infertility treatment: improving outcomes through standardization of laboratory procedures. Reproductive BioMedicine Online 35 391-399. (https://doi.org/10.1016/j. rbmo.2017.06.023)

Scott RT Jr, Upham KM, Forman EJ, Zhao T \& Treff NR 2013a Cleavagestage biopsy significantly impairs human embryonic implantation potential while blastocyst biopsy does not: a randomized and paired clinical trial. Fertility and Sterility $100624-630$.

Scott RT Jr, Upham KM, Forman EJ, Hong KH, Scott KL, Taylor D, Tao X \& Treff NR 2013b Blastocyst biopsy with comprehensive chromosome screening and fresh embryo transfer significantly increases in vitro fertilization implantation and delivery rates: a randomized controlled trial. Fertility and Sterility $100697-703$.

Schrurs BM, Winston RML \& Handyside AH 1993 Preimplantantion diagnosis of aneuploidy using fluorescent in situ hydridization:evaluation using a chromosome 18-specific probe. Human Reproduction 8 296-301. (https://doi.org/10.1093/oxfordjournals.humrep.a138040)

Shamonki MI, Jin H, Haimowitz Z \& Liu L 2016 Proof of concept: preimplantation genetic screening without embryo biopsy through analysis of cell-free DNA in spent embryo culture media. Fertility and Sterility 106 1312-1318. (https://doi.org/10.1016/j. fertnstert.2016.07.1112)

Steptoe PC \& Edwards RG 1978 Birth after the reimplantation of a human embryo. Lancet 2 366. (https://doi.org/10.1016/S0140-6736(78)929574)

Sturmey RG, Brison DR \& Leese HJ 2008 Symposium: innovative techniques in human embryo viability assessment. Assessing embryo viability by measurement of amino acid turnover. Reproductive BioMedicine Online 17 486-496. (https://doi.org/10.1016/S1472-6483(10)60234-9)

Tarín JJ, Vendrell FJ, Ten J, Blanes R, van Blerkom J \& Cano A 1996 The oxidizing agent tertiary butyl hydroperoxide induces disturbances in spindle organization, c-meiosis, and aneuploidy in mouse oocytes. Molecular Human Reproduction 2 895-901.

Tatone C, Heizenrieder T, Di Emidio G, Treffon P, Amicarelli F, Seidel T \& Eichenlaub-Ritter U 2011 Evidence that carbonyl stress by methylglyoxal exposureinduces DNA damage and spindle aberrations, affects mitochondrial integrity inmammalian oocytes and contributes to oocyte ageing. Human Reproduction 26 1843-1859. (https://doi.org/10.1093/ humrep/der140)

Taylor TH, Gitlin SA, Patrick JL, Crain JL, Wilson JM \& Griffin DK 2014 The origin, mechanisms, incidence and clinical consequences of chromosomal mosaicism inhumans. Human Reproduction Update $\mathbf{2 0}$ 571-581. (https://doi.org/10.1093/humupd/dmu016)

Taylor TH, Griffin DK, Katz SL, Crain JL, Johnson L \& Gitlin S 2016 Technique to 'map' chromosomal mosaicism at the blastocyst stage. Cytogenetic and Genome Research 149 262-266. (https://doi. org/10.1159/000449051)

Thornhill AR \& Snow K 2002 Molecular diagnostics in preimplantation genetic diagnosis. Journal of Molecular Diagnostics 4 11-29. (https://doi. org/10.1016/S1525-1578(10)60676-9)

Thornhill AR, Handyside AH, Ottolini C, Natesan SA, Taylor J, Sage K, Harton G, Cliffe K, Affara N, Konstantinidis M et al. 2015 Karyomapping-a comprehensive means of simultaneous monogenic and cytogenetic PGD: comparison with standard approaches in real time for Marfan syndrome. Journal of Assisted Reproduction and Genetics 32 347-356. (https://doi.org/10.1007/s10815-014-0405-y)

Tomlin G \& Borgetto B 2011 Research pyramid: a new evidencebased practice model for occupational therapy. American Journal of Occupational Therapy 65 189-96. (https://doi.org/10.5014/ ajot.2011.000828)

Traversa MV, Marshall J, McArthur S \& Leigh D 2011 The genetic screening of preimplantation embryos by comparative genomic hybridisation. Reproductive Biology 11 (Supplement 3) 51-60.

Treff NR \& Scott RT Jr 2013 Four-hour quantitative real-time polymerase chain reaction-based comprehensive chromosome screening and accumulating evidence ofaccuracy, safety, predictive value, and clinical efficacy. Fertility and Sterility 99 1049-1053. (https://doi.org/10.1016/j. fertnstert.2012.11.007)

Treff NR, Northrop LE, Kasabwala K, Su J, Levy B \& Scott RT Jr 2011 Single nucleotide polymorphism microarray-based concurrent screening of 24-chromosome aneuploidy and unbalanced translocations in preimplantation human embryos. Fertility and Sterility 95 1606-1612. (https://doi.org/10.1016/j.fertnstert.2010.11.004)

Treff NR, Tao X, Ferry KM, Su J, Taylor D \& Scott RT Jr 2012 Development and validation of an accurate quantitative real-time polymerase chain reaction-based assay for human blastocyst comprehensive chromosomal aneuploidy screening. Fertility and Sterility 97 819-24. (https://doi. org/10.1016/j.fertnstert.2012.01.115)

Treff NR, Zhan Y, Tao X, Olcha M, Han M, Rajchel J, Morrison L, Morin SJ \& Scott RT Jr 2017 Levels of trophectoderm mitochondrial DNA do not predict the reproductive potential of sibling embryos. Human Reproduction 32 954-962.

Turner K, Fowler K, Fonseka G, Griffin DK \& Ioannou D 2016 Multicolor detection of every chromosome as a means of detecting mosaicism and nuclear organization in human embryonic nuclei. Panminerva Medica 58 175-190.

Twisk M, Mastenbroek S, Hoek A, Heineman MJ, van der Veen F, Bossuyt PM, Repping S \& Korevaar JC 2008 No beneficial effect of preimplantation genetic screeningin women of advanced maternal age with a high risk for embryonic aneuploidy. Human Reproduction 23 2813-2817. (https://doi.org/10.1093/humrep/den231)

Ubaldi FM, Capalbo A, Colamaria S, Ferrero S, Maggiulli R, Vajta G, Sapienza F, Cimadomo D, Giuliani M \& Gravotta E 2015 Reduction of multiple pregnancies in the advanced maternal age population after implementation of an elective single embryo transfer policy coupled with enhanced embryo selection: pre- and post-intervention study. Human Reproduction 30 2097-2106. (https://doi.org/10.1093/humrep/dev159)

Vanneste E, Voet T, Melotte C, Debrock S, Sermon K, Staessen C, Liebaers I, Fryns JP, D'Hooghe T \& Vermeesch JR 2009 What next for preimplantation genetic screening? High mitotic chromosome instability rate provides the biological basis for the low success rate. Human Reproduction 24 2679-2682. (https://doi.org/10.1093/humrep/dep266)

Van Echten-Arends J, Mastenbroek S, Sikkema-Raddatz B, Korevaar JC, Heineman MJ, Van Der Veen F \& Repping S 2011 Chromosomal mosaicism in human preimplantation embryos: a systematic review. Human Reproduction Update 17 620-627. (https://doi.org/10.1093/ humupd/dmr014) 
Vázquez-Diez C \& FitzHarris G 2018 Causes and consequences of chromosome segregation error in preimplantation embryos. Reproduction 155 R63-R76.

Vázquez-Diez C, Yamagata K, Trivedi S, Haverfield J \& FitzHarris G 2016 Micronucleus formation causes perpetual unilateral chromosome inheritance in mouse embryos. PNAS 113 626-631.

Verlinsky Y, Ginsberg N, Lifchez A, Valle J, Moise J \& Strom CM 1990 Analysis of the first polar body: preconception genetic diagnosis. Human Reproduction 5 826-829. (https://doi.org/10.1093/oxfordjournals. humrep.a137192)

Verlinsky Y, Rechitsky S, Schoolcraft W, Strom C \& Kuliev A 2001 Preimplantation diagnosis for Fanconi anemia combined with HLA matching. JAMA 285 3130-3133. (https://doi.org/10.1001/jama.285.24.3130)

Victor AR, Brake AJ, Tyndall JC, Griffin DK, Zouves CG, Barnes FL \& Viotti M 2017 Accurate quantitation of mitochondrial DNA reveals uniform levels in human blastocysts irrespective of ploidy, age, or implantation potential. Fertility and Sterility 107 34-42. (https://doi. org/10.1016/j.fertnstert.2016.09.028)

Wells D, Sherlock JK, Handyside AH \& Delhanty JD 1999 Detailed chromosomal and molecular genetic analysis of single cells by whole genome amplification and comparative genomic hybridisation. Nucleic Acids Research 27 1214-1218. (https://doi.org/10.1093/nar/27.4.1214)

Wells D, Escudero T, Levy B, Hirschhorn K, Delhanty JD \& Munné S 2002 First clinical application of comparative genomic hybridization and polar body testing for preimplantation genetic diagnosis of aneuploidy. Fertility and Sterility 78 543-549. (https://doi.org/10.1016/S00150282(02)03271-5)

Wells D, Kaur K, Grifo J, Glassner M, Taylor JC, Fragouli E \& Munné S 2014 Clinical utilisation of a rapid low-pass whole genome sequencing technique for the diagnosis of aneuploidy in human embryos prior to implantation. Journal of Medical Genetics 51 553-562. (https://doi. org/10.1136/jmedgenet-2014-102497)

Wilton L 2005 Preimplantation genetic diagnosis and chromosome analysis of blastomeres using comparative genomic hybridization. Human Reproduction Update 11 33-41. (https://doi.org/10.1093/ humupd/dmh050)

Wolstenholme J 1996 Confined placental mosaicism for trisomies 2, 3, $7,8,9,16$, and 22: their incidence, likely origins, and mechanisms for cell lineage compartmentalization. Prenatal Diagnosis 16 511-524. (https://doi.org/10.1002/(SICI)1097-0223(199606)16:6<511::AIDPD904>3.0.CO;2-8)
Xu J, Fang R, Chen L, Chen D, Xiao JP, Yang W, Wang H, Song X, Ma T \& Bo S 2016 Noninvasive chromosome screening of human embryos by genome sequencing of embryo culture medium for in vitro fertilization. PNAS 113 11907-11912. (https://doi.org/10.1073/pnas.1613294113)

Yang Z, Liu J, Collins GS, Salem SA, Liu X, Lyle SS, Peck AC, Sills ES \& Salem RD 2012 Selection of single blastocysts for fresh transfer via standard morphology assessment alone and with aCGH for good prognosis IVF patients: results from a randomized pilot study. Molecular Cytogenetics 5 24. (https://doi.org/10.1186/1755-8166-5-24)

Yang Z, Zhang J, Salem SA, Liu X, Kuang Y, Salem RD \& Liu J 2014 Selection of competent blastocysts for transfer by combining time-lapse monitoring and array $\mathrm{CGH}$ testing for patients undergoing preimplantation genetic screening: a prospective study with sibling oocytes. BMC Medical Genomics 7 38. (https://doi.org/10.1186/1755-8794-7-38)

Yuan L, Liu JG, Hoja MR, Wilbertz J, Nordqvist K \& Höög C 2002 Female germ cell aneuploidy and embryo death in mice lacking the meiosisspecific protein SCP3. Science 296 1115-1118. (https://doi.org/10.1126/ science.1070594)

Zamani Esteki M, Dimitriadou E, Mateiu L, Melotte C, Van der Aa N, Kumar P, Das R, Theunis K, Cheng J, Legius E et al. 2015 Concurrent whole-genome haplotyping and copy-number profiling of single cells. American Journal of Human Genetics 96 894-912. (https://doi. org/10.1016/j.ajhg.2015.04.011)

Zheng X, Liu P, Chen G, Qiao J, Wu Y \& Fan M 2008 Viability of frozenthawed human embryos with one-two blastomeres lysis. Journal of Assisted Reproduction and Genetics 25 281-285. (https://doi. org/10.1007/s10815-008-9224-3)

Zheng H, Jin H, Liu L, Liu J \& Wang WH 2015 Application of nextgeneration sequencing for 24-chromosome aneuploidy screening of human preimplantation embryos. Molecular Cytogenetics 8 38. (https:// doi.org/10.1186/s13039-015-0143-6)

Received 13 November 2017

First decision 11 December 2017

Revised manuscript received 5 March 2018

Accepted 23 March 2018 